Canadian Journal of Fisheries and Aquatic Sciences

Canadian Science Publishing Journal canadien des sciences halieutiques et aquatiques

\title{
Temperature regimes, growth, and food consumption for female and male adult walleye in Lake Huron and Lake Erie: a bioenergetics analysis
}

\begin{tabular}{|c|c|}
\hline Journal: & Canadian Journal of Fisheries and Aquatic Sciences \\
\hline Manuscript ID & cjfas-2017-0280.R1 \\
\hline Manuscript Type: & Article \\
\hline Date Submitted by the Author: & 17-Nov-2017 \\
\hline Complete List of Authors: & $\begin{array}{l}\text { Madenjian, Charles; U.S. Geological Survey, } \\
\text { Hayden, Todd; US Geological Survey } \\
\text { Peat, Tyler; Carleton University Department of Biology, Department of } \\
\text { Biology } \\
\text { Vandergoot, Christopher; US Geological Survey } \\
\text { Fielder, David; Michiganm DNR, Fisheries } \\
\text { Gorman, Ann Marie; Fairport Fish Research Station, Ohio Department of } \\
\text { Natural Resources } \\
\text { Pothoven, Steven; Great Lakes Environmental Research Lab - NOAA } \\
\text { Dettmers, John; Great Lakes Fishery Commission } \\
\text { Cooke, Steven; Carleton University } \\
\text { Zhao, Yingming; Ontario Ministry of Natural Resources } \\
\text { Krueger, Charles; Michigan State University, Fisheries and Wildlife }\end{array}$ \\
\hline $\begin{array}{r}\text { Is the invited manuscript for } \\
\text { consideration in a Special } \\
\text { Issue? : }\end{array}$ & $\mathrm{N} / \mathrm{A}$ \\
\hline Keyword: & $\begin{array}{l}\text { bioenergetics modeling, food availability, interbasin variability, interlake } \\
\text { variability, temperature regime }\end{array}$ \\
\hline
\end{tabular}

\section{SCHOLARONE \\ Manuscripts}


Temperature regimes, growth, and food consumption for female and male adult walleye in Lake Huron and Lake Erie: a bioenergetics analysis

Charles P. Madenjian, Todd A. Hayden, Tyler B. Peat, Christopher S. Vandergoot,

David G. Fielder, Ann Marie Gorman, Steven A. Pothoven, John M. Dettmers,

Steven J. Cooke, Yingming Zhao, and Charles C. Krueger

C.P. Madenjian. US Geological Survey, Great Lakes Science Center, 1451 Green Road, Ann Arbor, MI 48105, USA.

T.A. Hayden. Michigan State University, Department of Fisheries and Wildlife, Hammond Bay Biological Station, 11188 Ray Road Millersburg, MI 49759, USA.

T.B. Peat and S.J. Cooke. Fish Ecology and Conservation Physiology Laboratory, Department of Biology, Carleton University, Ottawa, ON K1S 5B6, Canada.

14 C.S. Vandergoot. US Geological Survey, Great Lakes Science Center, Lake Erie Biological

15 Station, Sandusky, OH 44870, USA.

16 D.G. Fielder. Michigan Department of Natural Resources, Lake Huron Research Station, 160

17 Fletcher Street, Alpena, MI 49707, USA.

18 A. Gorman. Ohio Department of Natural Resources, Fairport Harbor Fisheries Research

19 Station, 1190 High Street, Fairport Harbor, OH 44077, USA.

20 S.A. Pothoven. National Oceanic and Atmospheric Administration, Great Lakes Environmental

21 Research Laboratory, Lake Michigan Field Station, 1431 Beach Street, Muskegon, MI 49441, 22 USA.

23 J.M. Dettmers. Great Lakes Fishery Commission, 2100 Commonwealth Boulevard, Suite 100, 24 Ann Arbor, MI 48105, USA.

25 Y. Zhao. Ontario Ministry of Natural Resources and Forestry, Aquatic Research and Monitoring

26 Section, Lake Erie Fisheries Station, 320 Milo Road, Wheatley, ON NOP 2P0, Canada.

27 C.C. Krueger. Michigan State University, Center for Systems Integration and Sustainability,

281405 South Harrison Road, East Lansing, MI 48823, USA.

29

Corresponding author: Charles P. Madenjian (e-mail: cmadenjian@usgs.gov). 
32 Abstract. Bioenergetics modeling was used to assess the relative importance of food availability

33 and water temperature in determining walleye (Sander vitreus) growth. Temperature regimes

34 experienced by both female and male adult walleye in three basins of Lake Huron and in Lake

35 Erie were determined by use of surgically implanted temperature loggers and acoustic telemetry.

36 Temperatures experienced by walleye were higher in Lake Erie than in Lake Huron. Walleye

37 from Lake Erie grew at nearly double the rate of walleye from Lake Huron, and weight at age for

38 adult females averaged about $50 \%$ greater than that for adult males in both lakes. Food

39 consumption rate for an average adult walleye in Lake Erie was nearly twice as high as that in

40 Lake Huron. Interbasin and interlake variability in temperature regimes accounted for a

41 moderate degree of variability in walleye growth. We concluded that the driver for faster growth

42 in Lake Erie compared with Lake Huron was higher food availability in Lake Erie compared

43 with Lake Huron. The sex difference in temperature regimes explained $15 \%$ of the sex

44 difference in Lake Erie walleye growth.

46 Keywords: acoustic telemetry; bioenergetics modeling; food availability; interbasin variability;

47 interlake variability; sex differences; temperature loggers; temperature regime. 


\section{Introduction}

For a given species of fish, individual-level growth of fish is a function of food availability and the temperature regime experienced by the fish (Hewett and Johnson 1992; Jobling 1994;

51 Quinn and Deriso 1999; Enberg et al. 2008). Food availability is a complex function of several

52 factors, including prey abundance, prey size, and handling times (Werner 1974; Persson and

53 Greenberg 1990; Rennie and Venturelli 2015). Typically, metabolic costs for the fish increase

54 with increasing water temperature, and metabolic costs represent a substantial energy loss for

55 fish (Hewett and Johnson 1992; Jobling 1994; Quinn and Deriso 1999; Enberg et al. 2008).

56 Thus, if the rate of food consumption is identical in two aquatic ecosystems, and other factors

57 affecting growth other than water temperature are also identical across the two ecosystems, then

58 fish growth would be expected to be faster in the aquatic ecosystem with the lower temperatures

59 experienced by fish compared with fish growth in the other aquatic ecosystem, owing to higher

60 metabolic costs in the warmer ecosystem (Hewett and Johnson 1992; Kao et al. 2015a, 2015b).

61 Bioenergetics modeling has proven invaluable in assessing the effects of various factors,

62 including temperature regime, on fish growth (Chipps and Wahl 2008; Madenjian 2011;

63 Deslauriers et al. 2017). A fish bioenergetics model represents an energy budget for a fish.

64 Energy input via food consumption is equal to metabolic losses, waste losses, and growth:

$$
\mathrm{C}=(\mathrm{R}+\mathrm{A}+\mathrm{SDA})+(\mathrm{F}+\mathrm{U})+\mathrm{G}
$$

66 where $\mathrm{C}=$ consumption, $\mathrm{R}=$ standard metabolism, $\mathrm{A}=$ energy expenditure due to activity, SDA

$67=$ specific dynamic action (energy required to digest food), $\mathrm{F}=$ egestion, $\mathrm{U}=$ excretion, and $\mathrm{G}=$

68 growth. Standard metabolism is typically modeled as an exponential function of water

69 temperature. Bioenergetics model applications to evaluate the effects of various factors on fish

70 growth are well illustrated in the study by Hayward and Margraf (1987), who used bioenergetics 
71 modeling to show that faster growth of yellow perch (Perca flavescens) in the central basin of

72 Lake Erie compared with the western basin of Lake Erie was due to an interbasin difference in

73 food availability rather than an interbasin difference in temperature regime.

74 Coupling archival temperature tag technology with acoustic telemetry has recently enabled 75 researchers to record thermal histories of fish within different basins of the same lake, as well as

76 within lakes connected by waterways (Cooke et al. 2013; Hayden et al. 2014; Peat et al. 2015).

77 By constructing an appropriate acoustic receiver network, interbasin and/or interlake movement

78 of fish can be detected. Implanting both an acoustic transmitter and an archival temperature tag

79 in each fish, and subsequent monitoring of any interbasin and interlake movements of the fish

80 using acoustic telemetry, can be used by researchers to determine temperature regimes

81 experienced by fish while confined to a specific basin or lake.

82 To date, the effects of both interbasin and interlake variability in temperatures experienced by

83 fish on fish growth in a two-lake system, with a connecting waterway between the two lakes,

84 have not been investigated. Moreover, the effect of a difference in temperature regimes between

85 the sexes of a fish population on the difference in growth between the sexes has yet to be

86 assessed for any fish population. Use of archival temperature tagging and acoustic telemetry, in

87 conjunction with fish bioenergetics modeling, affords the opportunity to pursue these new lines

88 of research. In turn, these new lines of research may have fishery management implications,

89 because knowledge of movement and spatial ecology of fishes provides critical information to

90 managers about how fishes are distributed in both space and time (Lucas and Baras 2000;

91 Landsman et al. 2011). For example, bioenergetics analysis of growth of a piscivorous fish

92 within a two-lake system may be useful in accurately characterizing the fish's role as a piscivore

93 in both lakes. 
94 Walleye (Sander vitreus) populations support valuable recreational and/or commercial

95 fisheries in many North American lakes, reservoirs, and rivers (Feiner and Höök 2015).

96 Moreover, this species fulfills the ecological role as a top predator in the aquatic ecosystems that

97 it inhabits (Feiner and Höök 2015; He et al. 2015). Female walleye grow substantially faster

98 than male walleye, but reasons for this sexually dimorphic growth are not clear (Bozek et al.

99 2011; Rennie and Venturelli 2015). In the Laurentian Great Lakes, the most valuable walleye

100 fisheries are situated in Lake Huron and Lake Erie (Roseman et al. 2008; Melstrom and Lupi

101 2013; Fielder et al. 2014). Despite the importance of the Lake Huron and Lake Erie walleye

102 fisheries, a direct and rigorous comparison of walleye growth in Lake Huron with walleye

103 growth in Lake Erie has yet to be undertaken.

104 Walleye in Lake Huron exhibit three migration behaviors, as elucidated from an acoustic 105 telemetry study (Hayden et al. 2014). Walleye may reside in Saginaw Bay throughout the year

106 or out-migrate to the main basin of Lake Huron for residence during the summer and fall. Those

107 walleye out-migrating to the main basin either reside in the northern main basin or the southern

108 main basin (Hayden et al. 2014). Walleye remaining in Saginaw Bay are expected to experience

109 warmer temperatures than those walleye out-migrating to the main basin, while food availability

110 for walleye is presumably higher in Saginaw Bay than in the main basin (Fielder et al. 2014;

111 Hayden et al. 2014; Peat et al. 2015).

112 The primary goals of our study were to compare walleye growth in Lake Huron with walleye

113 growth in Lake Erie and to assess the relative importance of food availability and temperature

114 regime as determinants of walleye growth in the Lake Huron - Lake Erie system. A secondary

115 goal of our study was to evaluate the effect of sex differences in temperature regimes on sex

116 differences in walleye growth. Specific objectives included: (i) use temperature loggers and 
117 acoustic telemetry to determine temperatures experienced by female and male walleye in

118 Saginaw Bay, the northern main basin of Lake Huron, the southern main basin of Lake Huron,

119 and Lake Erie, (ii) develop growth trajectories for female and male walleye in both Lake Huron

120 and Lake Erie, and then compare growth between the two lakes, (iii) use bioenergetics modeling

121 to estimate food consumption by female and male walleye in Saginaw Bay, northern main basin

122 of Lake Huron, southern main basin of Lake Huron, and Lake Erie, (iv) using a bioenergetics

123 modeling framework, exchange temperature regimes experienced by walleye between basins and

124 lakes to assess the effects of interbasin and interlake variability in temperature regimes

125 experienced by walleye on walleye growth, and $(v)$ again using a bioenergetics modeling

126 framework, exchange temperature regimes experienced by walleye between the sexes to evaluate

127 the effect of sex differences in temperature regimes on sex differences in walleye growth.

\section{Materials and methods}

130 Field methods

131 Walleye in this study were captured and tagged as part of a large project to understand

132 movement of two adfluvial walleye populations in the Great Lakes. A detailed description of

133 walleye capture and tagging is found elsewhere (Hayden et al. 2014; Peat et al. 2015). Walleye

134 in spawning condition were captured using boat-mounted electroshocking gear in the

135 Tittabawassee River (Lake Huron watershed) immediately downstream of Dow Dam (Midland,

$136 \mathrm{MI}$ ) and near Orleans Park in the Maumee River (tributary to Lake Erie) during March-April in

1372011 and 2012. The primary spawning area in the Tittabawassee River is located approximately

$138 \quad 2-3 \mathrm{~km}$ downstream of the Dow Dam and approximately $100 \mathrm{~km}$ upstream of the mouth of the

139 Saginaw River in Saginaw Bay. Primary walleye spawning grounds in the Maumee River are 
140 located approximately $25-30 \mathrm{~km}$ upstream of the Maumee River mouth in Lake Erie. After

141 capture, biological measurements (total length in millimeters, sex) and dorsal fin spine clips were

142 collected from each walleye chosen for transmitter implanting and paired t-bar tags (Floy Tag,

143 Inc., Seattle, WA) were inserted below the base of the second dorsal fin. T-bar tags allowed

144 identification of walleye during the implanting process and informed anglers of the presence of

145 an internal acoustic transmitter in the event the fish was caught after release. Dorsal fin spine

146 clips were used for non-lethal age (in years) estimation. Fish were then transferred to streamside

147 holding tanks for surgical implantation of an acoustic transmitter and a temperature logger.

148 Walleye selected for implanting transmitters in the Maumee and Tittabawassee rivers were

149 greater than $381 \mathrm{~mm}$, which represented the minimum length limit for recreational angling limit

150 for Michigan waters of Lake Huron and Ohio waters of Lake Erie during 2011-2012. In total,

151199 walleye were implanted with transmitters in the Tittabawassee River and 200 walleye were

152 implanted with transmitters in the Maumee River in 2011. In 2012, 60 walleye were implanted

153 with transmitters in the Tittabawassee River and 33 walleye were implanted with transmitters in

154 the Maumee River. Our research project was reviewed and approved by the Carleton University

155 Animal Care Committee in accordance with the Canadian Council of Animal Care Guidelines

156 for the Use of Fish in Research (Project number 8890; Approval number B10-29).

157 Each walleye was implanted with an acoustic transmitter programmed to emit a unique code

158 (frequency of $69 \mathrm{kHz}$ ) at random intervals between 60 seconds and 180 seconds (mean: 120

159 seconds) (Vemco, Halifax, Nova Scotia; model V16-4x; 16 mm dia X 86 mm, 24 g; battery life

$160=1338$ days). Each acoustic transmitter was outfitted with an iButton temperature logger

161 (DS1921z; resolution $= \pm 0.1^{\circ} \mathrm{C}$, precision $=0.2 \pm 0.3{ }^{\circ} \mathrm{C}$, accuracy $=0.4 \pm 0.3{ }^{\circ} \mathrm{C}$, Maxim

162 Integrated Products, Inc., Sunnyvale, CA) programmed to record temperatures at four-hour 
163 intervals for a period of approximately one year (Donaldson et al. 2009). All iButtons were

164 attached to acoustic transmitters using hot glue, and dipped in an inert waterproof coating (Plasti

165 Dip, Performix Brand, Blaine, MN) prior to implantation.

166 Walleye were anesthetized prior to surgery using a Smith-Root (Vancouver, WA) portable

167 electroanesthesia system operating at $35 \mathrm{~V}$ pulsed direct current. Treatments of 3 seconds

168 induced stage-4 anesthesia for several minutes (Vandergoot et al. 2011). All surgeries were

169 conducted on fish supported in a v-shaped surgical table lined with soft non-slip material.

170 Walleye received a constant supply of fresh river water pumped across gills during surgery and

171 all surgical tools and transmitters were cleaned with povidone iodine prior to surgery. Acoustic

172 transmitters with attached iButtons were inserted into the coelomic cavity through a small

173 incision located along the ventral side of each fish, posterior to the pelvic girdle. Incisions were

174 closed using 2-3 interrupted sutures (absorbable monofilament, PDS-II, 3-0, Ethicon,

175 Somerville, $\mathrm{NH})$. After surgery, fish were placed in holding tanks until fish were able to

176 maintain balance in the water (approximately 30 minutes), and then fish were released near the

177 capture site.

178 The acoustic receiver array was deployed as part of the Great Lakes Acoustic Telemetry

179 Observation System network (http://data.glos.us/glatos) and consisted of approximately 140

180 omnidirectional receivers operating at $69 \mathrm{kHz}$ (VR2W, Vemco, Halifax, Nova Scotia). Hayden

181 et al. (2014) and Peat et al. (2015) provide complete details of anchoring acoustic receivers and

182 receiver line detection probabilities. All receivers were suspended in the water column and

183 retrieved annually for maintenance and data download. Deployment locations of acoustic

184 receivers during 2011-2012 in Lake Huron consisted of multiple receivers near the

185 Tittabawassee and Saginaw river mouths, double receiver lines located across Saginaw Bay, and 
186 multiple-receiver lines extending perpendicular to the shoreline to depths $<40 \mathrm{~m}$ (extending 3-10

187 km offshore) (Fig. 1). Receiver lines were deployed to monitor walleye movements in and out of 188 the Saginaw Bay, movements in and out of the Tittabawassee and Saginaw rivers, and nearshore 189 movements in Lake Huron. Acoustic receivers were deployed in the St. Clair River flowing out 190 of Lake Huron, and Detroit River to monitor walleye movement between Lake Huron and Lake

191 Erie through the Huron-Erie corridor (Fig. 1). Acoustic receivers were deployed near the mouth

192 of the Maumee River in Lake Erie to monitor walleye movements in and out of the river.

193 Thermal data were obtained via returned transmitter/iButtons from fish caught in recreational

194 and commercial fisheries. A \$100 USD reward was offered to anyone that returned the acoustic

195 transmitter with the attached iButton to the investigators. All acoustic detection data were

196 screened for false positives caused by environmental noise and signal collisions using the short-

197 interval criteria described by Pincock (2009). False detections were detections that were not

198 accompanied by at least one other detection from the same transmitter on the same receiver

199 within 1 hour and were removed from the analysis. Of all of the detections, $99 \%$ of them passed

200 the false detection filter.

201 We used acoustic telemetry detections to classify the walleye recaptured by anglers and 202 commercial fishers into four geographic areas: (1) northern main basin of Lake Huron, (2)

203 southern main basin of Lake Huron, (3) Saginaw Bay, and (4) Lake Erie (Fig. 1). Please refer to 204 Hayden et al. (2014) and Peat et al. (2015) for more details on the classification assignments.

\section{Temperature regimes}

207 We followed the procedure described by Bergstedt et al. (2003), Madenjian et al. (2003, 208 2006), and He et al. (2015) to develop temperature regimes for both female and male walleye 
209 from each of the above-mentioned four geographic areas. The calendar year was divided into

210 half-month intervals. For each combination of geographic area and sex, temperatures recorded

211 on the iButton temperature loggers were averaged within each half-month interval, and the

212 standard error of the mean was also calculated. The mean temperature for each half-month

213 interval was assigned to the midpoint day, in time, for the half-month interval. Temperatures for

214 days between consecutive midpoints were estimated via linear interpolation. Thus, each day of

215 the calendar year was assigned a temperature.

216 In 15 cases, the calculated mean temperature for the half-month interval was less than $0.10^{\circ} \mathrm{C}$.

217 To successfully perform the bioenergetics model simulations, all calculated mean temperatures

218 less than $0.10{ }^{\circ} \mathrm{C}$ were assigned the value of $0.10^{\circ} \mathrm{C}$. Waste loss components of the

219 bioenergetics model yielded inaccurate estimates of waste losses for temperatures less than 0.10

$220{ }^{\circ} \mathrm{C}$ (Kao et al. 2015a, 2015b), and therefore these assignments were necessary to successfully

221 complete the bioenergetics modeling.

222 We were well justified in developing temperature regimes by sex and geographic area, for

223 four reasons. First, two of the objectives of our study were to assess the effects of interbasin and

224 interlake variability in temperature regimes on walleye growth and to assess the effect of the sex

225 difference in temperature regimes on the sex difference in walleye growth. Development of

226 temperature regimes by sex and geographic area was necessary to accomplish these two

227 objectives. Second, previous research has shown that, on average,: (i) surface water

228 temperatures in Saginaw Bay are higher than those in the main basin of Lake Huron, (ii) surface

229 water temperatures in the southern section of Lake Huron's main basin are higher than those in

230 the northern main basin of Lake Huron, and (iii) surface water temperatures in Lake Erie are

231 higher than those in any of the basins of Lake Huron (Moukomla and Blanken 2016). Third, 
232 habitat use may vary with sex both in the Saginaw Bay walleye population and in the Lake Erie

233 walleye population (Madenjian et al. 1998; Wang et al. 2007). Fourth, female walleye grow

234 considerably faster than male walleye (Bozek et al. 2011; Rennie and Venturelli 2015).

235

\section{Growth trajectories}

237 We estimated growth trajectories for both female and male walleye from Lake Huron based

238 on data from annual gillnet surveys conducted by the Michigan Department of Natural Resources

239 (DNR) each September in Saginaw Bay (Fielder and Thomas 2014). Total length (TL, to the

240 nearest millimeter), weight (to the nearest gram), and age (in years) of each walleye caught in the

241 gill nets were determined. We pooled survey data from years 2010-2012, which closely

242 corresponded with the years of our acoustic telemetry study, and then fitted von Bertalanffy

243 growth curves to the TL at age data for both sexes. In addition, a weight-length regression curve

244 was fitted to TL and weight data for each sex. Total lengths at age for ages 3-13 years were

245 calculated from the fitted von Bertalanffy growth curves for both sexes. Then, these TLs at age

246 were substituted into the fitted weight-length regression equations to estimate weights at age.

247 We focused on ages 3-13 years because this range of ages is used in the population models

248 developed for the Lake Huron walleye population (Fielder and Bence 2014; Fielder and Thomas

249 2014; He et al. 2015). Walleye growth trajectories were assumed not to vary across the basins

250 (i.e., northern main basin, southern main basin, and Saginaw Bay) of Lake Huron. A similar

251 assumption was made by He et al. (2015) in quantifying piscivory patterns in Lake Huron.

252 Standard errors were calculated for weights at age by first calculating standard errors for TLs at

253 age, using routines described by Ogle (2016), and then substituting the error bounds for TLs at

254 age into the fitted weight-length equations. 
255 Growth trajectories for Lake Erie were based on data from annual gillnet surveys conducted

256 by the Michigan DNR, Ohio DNR, and Ontario Ministry of Natural Resources and Forestry

257 (OMNRF) each October in the western and central basins of Lake Erie (Ohio Division of

258 Wildlife 2011, 2012, 2013). Again, TL (to the nearest millimeter), weight (to the nearest gram),

259 and age (in years) of each walleye caught in the gill nets were determined, and survey data from

260 years 2010-2012 were pooled. Von Bertalanffy growth curves were fitted to TLs at age for both

261 sexes, and weight-length regression curves were fitted to TL and weight data for both sexes.

262 Weights at age were estimated by substituting TLs at age into the fitted weight-length regression

263 equations. Standard errors were calculated for weights at age, using the same procedures

264 described above.

265 To determine whether walleye growth significantly differed between the two lakes and

266 between the sexes, we applied $t$ tests for paired comparisons to the above-mentioned estimated

267 weights at ages 3-13. Specifically, $t$ tests for paired comparisons were used to: ( $i$ ) compare

268 weight at age of Lake Huron female walleye with weight at age of Lake Erie female walleye, (ii)

269 compare weight at age of Lake Huron male walleye with weight at age of Lake Erie male

270 walleye, (iii) compare weight at age of Lake Huron female walleye with weight at age of Lake

271 Huron male walleye, and (iv) compare weight at age of Lake Erie female walleye with weight at

272 age of Lake Erie male walleye.

273

\section{Bioenergetics modeling: fit to observed growth}

275 The Wisconsin walleye bioenergetics model, originally developed by Kitchell et al. (1977)

276 and refined by Hewett and Johnson (1992), was used to estimate food consumption by both

277 female and male walleye in each of the four geographic areas. Bioenergetics model simulations 
278 were performed using the Fish Bioenergetics 4.0 software developed by Deslauriers et al. (2017).

279 The model was fit to observed growth, as represented by the growth trajectory, to estimate food 280 consumption. For each combination of geographic area and sex, the appropriate temperature 281 regime, as derived from our iButton temperature logger data, was used in the bioenergetics 282 model simulations. Each bioenergetics model simulation was one year in duration, and thus 10 283 simulations were run in order to estimate food consumption by an average walleye from age 3 284 through age 13 for each combination of geographic area and sex. The bioenergetics model 285 operated on a daily time step (Hewett and Johnson 1992).

286 With regard to bioenergetics modeling for Lake Huron walleye, inputs for diet composition, 287 prey energy density, and walleye energy density were taken from Pothoven et al. (2017).

288 Because 8 September represented the typical midpoint date for the duration of the Michigan 289 DNR gillnet survey in Saginaw Bay, we assigned 8 September as the starting day for the 290 bioenergetics model simulations. Spawning day was assigned 4 April for Lake Huron walleye 291 (Madenjian et al. 1998). Spawning was simulated by females and males losing $22.1 \%$ and $2.9 \%$, 292 respectively, of their body weight on the spawning day (Madenjian et al. 1998). Females and 293 males were assumed to mature by ages 5 and 4 years, respectively (Wang et al. 2009; Fielder 294 2014; Fielder and Thomas 2014).

295 With regard to bioenergetics modeling for Lake Erie walleye, diet composition was based on 296 stomach contents data for age-2 and older walleye caught by the Ohio DNR during monthly 297 bottom trawl surveys from May through October and fall gillnet surveys (late September through 298 early November) during 2000-2015 (Ohio Division of Wildlife 2016). Bottom trawls were 299 conducted from sunrise to sunset and gill nets were set overnight on the bottom or suspended 300 approximately $1.5-3 \mathrm{~m}$ from the surface. All fish were held on ice in coolers $<12$ hours until 
301 being processed. In the laboratory, total length of each walleye was measured to the nearest

302 millimeter, and wet weight was recorded to the nearest gram. For stomach contents analysis,

303 prey items were examined macroscopically, identified to the lowest taxonomic level possible,

304 and measured to the nearest millimeter. Whole prey items were measured for total length, while

305 partially digested items were measured for standard, fork, or backbone length. All prey lengths

306 were converted to total length when necessary, and subsequently converted to wet weight using

307 available data (Ohio Division of Wildlife 2016). Prey items were grouped into the following

308 eight diet categories: shiners (primarily emerald shiner (Notropis atherinoides)), clupeids

309 (primarily gizzard shad (Dorosoma cepedianum)), Morone spp. (primarily white perch (Morone

310 americana)), rainbow smelt (Osmerus mordax), yellow perch, round goby (Neogobius

311 melanostomus), miscellaneous fish (primarily rainbow trout (Oncorhynchus mykiss)), and

312 invertebrates (burrowing mayflies, other ephemeropterans, amphipods, Bythotrephes

313 longimanus, chironomids, other dipterans, isopods, and trichopterans). Wet weights of

314 individual prey were used to calculate percent diet composition of each prey category for each

315 walleye, and mean percent diet composition was calculated across individuals for each month

316 (May through October) (Table 1). Percent composition of unidentified fish was distributed

317 proportionally across the identified finfish species each month. Diet composition for April and

318 November was assumed to be equal to that for May and October, respectively. Diet composition

319 for December through March was assumed to be equal to the average diet composition for

320 months May and October. A total of 7860 walleye stomachs were examined. Of these, 3449

321 contained prey items and 4411 were empty.

322 Energy densities for gizzard shad, Morone spp., yellow perch, and round goby from Lake Erie

323 were taken from Kershner (1996) and Bunnell et al. (2005) (Table 2). Energy densities for 
324 miscellaneous fish and invertebrates from Lake Erie were based on previous studies (Cummins

325 and Wuycheck 1971; Pothoven et al. 2017). To determine energy densities of Lake Erie emerald

326 shiner and rainbow smelt, we used bottom trawling to sample emerald shiner and rainbow smelt

327 from Lake Erie during May-October 2005-2007. In total, three composite samples of emerald

328 shiners and five composite samples of rainbow smelt were homogenized in a blender. Number

329 of emerald shiners and rainbow smelt per composite ranged from 12 to 25 fish and from 10 to 23

330 fish, respectively. Energy density, in J/g wet weight, was determined for each composite using a

331 Parr 1261 isoperibol bomb calorimeter (Parr Instrument Company, Moline, IL), following the

332 procedure outlined by Pothoven et al. (2012). For both emerald shiners and rainbow smelt,

333 energy densities were averaged across the composite samples to determine mean energy density

334 (Table 2). Energy densities for Lake Erie walleye were determined by capturing 41 walleye in

335 Lake Erie using gill nets during May 2005 (Pothoven et al. 2008). Upon capture, each walleye

336 was individually wrapped in foil, bagged, and frozen until processing. In the laboratory, frozen

337 fish were homogenized using a commercial blender. To determine dry-to-wet mass, we dried a

$338 \quad 20-30 \mathrm{~g}$ subsample of ground fish tissue at $70^{\circ} \mathrm{C}$ to a constant mass (about 3 days). For energy

339 density (J/g wet weight), the dried material was ground with a mortar and pestle, and then a $1-\mathrm{g}$

340 subsample was combusted in a Parr 1261 isoperibol bomb calorimeter that was standardized with

341 benzoic acid. To estimate within-fish variability for bomb calorimetry, we initially quantified

342 energy density in triplicate. The mean coefficient of variation for individual fish was $1.02 \%(\mathrm{n}=$

343 10), thus, we subsequently quantified energy density using only one subsample per fish

344 following the procedure outlined by Pothoven et al. (2017). Walleye energy density increased

345 with increasing walleye weight, and therefore we fitted a straight line, using simple linear

346 regression analysis, to walleye energy density as a function of walleye weight. Walleye weights 
347 ranged from 487 to $6426 \mathrm{~g}$. We used the fitted regression line $\mathrm{ED}=7776+0.231 \mathrm{~W}$, where $\mathrm{ED}$

348 = walleye energy density $(\mathrm{J} / \mathrm{g}$ wet weight $)$ and $\mathrm{W}=$ walleye wet weight $(\mathrm{g})$, for the bioenergetics

349 modeling of Lake Erie walleye. Because energy density did not significantly differ between the

350 sexes of Lake Erie walleye, this fitted regression line was used for both sexes. Similarly, energy

351 density did not significantly differ between the sexes of Lake Huron walleye, and therefore the

352 walleye energy density function used by Pothoven et al. (2017) was applied to both sexes in our

353 Lake Huron simulations.

354 Because 15 October represented the typical midpoint date for the duration of the Ohio DNR

355 fall gillnet survey in Lake Erie, we assigned 15 October as the starting day for the Lake Erie

356 bioenergetics model simulations. Spawning day was assigned 10 April for Lake Erie walleye

357 (Ohio Division of Wildlife 2011, 2012, 2013). Again, spawning was simulated by females and

358 males losing $22.1 \%$ and $2.9 \%$, respectively, of their body weight on the spawning day. Females

359 and males were assumed to mature by ages 4 and 3 years, respectively (Ohio Division of

360 Wildlife 2011, 2012, 2013).

362 Bioenergetics modeling: exchanging temperature regimes between areas and sexes

363 Walleye growth is affected by both food availability and the temperature regime experienced

364 by the walleye. One of the steps in identifying which of these two factors is the more influential

365 determinant of walleye growth in the Lake Huron - Lake Erie system is to assess the scope for

366 changes in walleye growth brought about by geographic variation in temperature regimes.

367 Results from this scoping exercise can then be compared with observed geographic differences

368 in walleye growth within the Lake Huron - Lake Erie system solely attributable to food

369 availability, and then relative importance of the two factors can be determined. To assess the 
370 scope for changes in walleye growth brought about by geographic variation in temperature

371 regimes, we performed the following set of bioenergetics model simulations. For a specific

372 combination of geographic area and sex, walleye growth was predicted using the food

373 consumption schedule for that specific combination of geographic area and sex (as determined

374 by the fit-to-growth simulations) but replacing the temperature regime for that specific

375 combination of geographic area and sex with the temperature regimes for the other three

376 geographic areas and the same sex. The food consumption schedule was the total amount of

377 food consumed by an average walleye over the course of the year for each of the 10 simulation

378 years from age 3 through age 13 , as determined by the 10 fit-to-growth simulations. Observed

379 weight at age 3 was the starting walleye weight, and walleye growth was predicted over ages 4-

380 13. For each age between 4 and 13, predicted walleye weight was compared with observed 381 walleye weight. For example, consider the case of northern Lake Huron female walleye. We

382 predicted female walleye growth from age 3 through age 13, using the feeding schedule for

383 northern Lake Huron females and maintaining bioenergetics model inputs specific for northern

384 Lake Huron females other than temperature regime, under the following three temperature

385 regimes: (i) southern Lake Huron female walleye, (ii) Saginaw Bay female walleye, and (iii)

386 Lake Erie female walleye. The starting weight for each of these three scenarios was the

387 observed weight at age 3 for Lake Huron female walleye. For each of the three scenarios, 388 predicted weight at age was compared with observed weight at age for Lake Huron female 389 walleye. Percent changes from observed weight at age were recorded.

390 In our bioenergetics model simulations, we kept food consumption constant while subjecting

391 the fish to temperature regimes from other geographic areas in order to assess the effect of

392 geographic variation in temperature regimes on fish growth. Our approach was similar to that of 
393 Kao et al. (2015a, 2015b), who inputted the present-day food consumption schedule into fish

394 bioenergetics models while subjecting the fish to a temperature regime predicted for the future

395 using climate change models. The goal of the Kao et al. (2015a, 2015b) studies was to forecast

396 the effects of climate change on fish growth in the Laurentian Great Lakes.

397 To assess the effect of variability in temperature regimes between the sexes on walleye

398 growth, we performed the following set of bioenergetics model simulations. For a specific

399 combination of geographic area and sex, walleye growth was predicted using the food

400 consumption schedule for that specific combination of geographic area and sex (as determined

401 by the fit-to-growth simulations) but replacing the temperature regime for that specific

402 combination of geographic area and sex with the temperature regime for that specific geographic

403 area but for the opposite sex. Again, observed weight at age 3 was the starting walleye weight,

404 and walleye growth was predicted over ages 4-13. Predicted walleye weight was compared with

405 observed walleye weight for ages 4-13. Consider the case of northern Lake Huron female

406 walleye as an example. We predicted female walleye growth from age 3 through age 13, using

407 the feeding schedule for northern Lake Huron females and maintaining bioenergetics model

408 inputs specific for northern Lake Huron females other than temperature regime, but we replaced

409 the temperature regime for northern Lake Huron female walleye with the temperature regime for

410 northern Lake Huron male walleye. Initial weight was the observed weight at age 3 for Lake

411 Huron female walleye. Predicted weight at age was compared with observed weight at age for

412 Lake Huron female walleye over ages 4-13, and percent changes from observed weight at age

413 were recorded. We did not assess the effect of variation in food availability between the sexes

414 on the sex difference in walleye growth, because factors other than a sex difference in food

415 availability likely were responsible for faster growth by females compared with males (Bozek et 
416 al. 2011; Rennie and Venturelli 2015). In contrast, assessment of the effect of a sex difference in

417 temperature regimes on the sex difference in growth was a secondary goal of our study.

\section{Results}

\section{Temperature regimes}

421 Temperature data downloaded from temperature loggers implanted in 81 individuals ( $16 \%$ of

422 total number of implanted individuals) were used to derive temperature regimes experienced by

423 walleye. Temperature data from 5 females and 3 males were used to characterize the

424 temperature regimes for walleye inhabiting northern Lake Huron, whereas the temperature

425 regimes for walleye inhabiting southern Lake Huron were based on data from 7 females and 2

426 males. In addition, temperature data from 18 females and 17 males and from 13 females and 16

427 males were used to characterize the temperature regimes for walleye residing in Saginaw Bay

428 and Lake Erie, respectively. Ages of the walleye from Lake Huron ranged from 4 to 14 years,

429 and only one of these walleye was an age-14 fish. Similarly, ages of walleye from Lake Erie

430 ranged from 4 to 13 years.

431 On average, temperatures experienced by the walleye were lowest for northern Lake Huron

432 walleye and highest for Lake Erie walleye (Fig. 2). Over the course of the calendar year, mean

433 temperatures experienced by female and male walleye from northern Lake Huron were 8.7 and

$4348.6{ }^{\circ} \mathrm{C}$, respectively. Temperature regimes were slightly higher for southern Lake Huron walleye

435 compared with northern Lake Huron walleye, with female and male walleye from southern Lake

436 Huron experiencing average temperatures of 9.3 and $8.9^{\circ} \mathrm{C}$, respectively, over the course of the

437 calendar year. Saginaw Bay walleye experienced higher temperatures than walleye from the

438 main basin of Lake Huron, as female and male walleye from Saginaw Bay experienced mean 
439 temperatures of 10.8 and $10.5^{\circ} \mathrm{C}$, respectively, during the year (Fig. 2). Temperatures

440 experienced by female and male walleye from Lake Erie averaged 11.1 and $11.5^{\circ} \mathrm{C}$,

441 respectively. Thus, on average, temperature regimes for female walleye were higher than those

442 for male walleye in the main basin of Lake Huron and Saginaw Bay, whereas the temperature

443 regime for male walleye from Lake Erie averaged a higher value than the temperature regime for

444 female walleye from Lake Erie. Peak temperatures experienced by female walleye were 20.6,

$44521.3,23.8$, and $23.4{ }^{\circ} \mathrm{C}$ in northern Lake Huron, southern Lake Huron, Saginaw Bay, and Lake

446 Erie, respectively (Fig. 2). Peak temperatures experienced by male walleye were 20.6, 21.8,

44722.5 , and $25.1^{\circ} \mathrm{C}$ in northern Lake Huron, southern Lake Huron, Saginaw Bay, and Lake Erie,

448 respectively.

\section{Growth trajectories}

$451 \quad$ Walleye attained much larger sizes in Lake Erie than in Lake Huron (Fig. 3; Table 3). Age-3

452 female walleye in Lake Erie were 2.5 times greater in weight than age-3 female walleye in Lake

453 Huron, and age-3 male walleye in Lake Erie were 2.2 times greater in weight than age-3 male

454 walleye in Lake Huron. At age 8, female and male walleye in Lake Erie were 84\% and 72\%,

455 respectively, greater in weight than female and male walleye in Lake Huron (Fig. 3). At age 13,

456 mean weight of female walleye, as estimated from our analysis, was $3.2 \mathrm{~kg}$ in Lake Erie

457 compared with $2.1 \mathrm{~kg}$ in Lake Huron. For males, we estimated mean weight in Lake Erie to be

$458 \quad 1.9 \mathrm{~kg}$ compared with $1.2 \mathrm{~kg}$ in Lake Huron. Averaging across ages 3-13, female walleye from

459 Lake Erie exceeded female walleye from Lake Huron in weight by $92 \%$. Similarly, averaging

460 across ages 3-13, male walleye from Lake Erie were $78 \%$ greater in weight than male walleye 
461 from Lake Huron. Averaging across ages and sexes, walleye growth in Lake Erie was 85\% 462 greater than walleye growth in Lake Huron.

463 Females grew substantially faster than males in both Lake Huron and Lake Erie (Fig. 3).

464 Averaging across ages 3-13, female walleye from Lake Huron were 47\% greater in weight than 465 Lake Huron male walleye. Similarly, averaging across ages 3-13, female walleye from Lake 466 Erie were $56 \%$ greater in weight than Lake Erie male walleye.

467 Based on results from $t$ tests for paired comparisons, Lake Erie female walleye at a given age 468 were significantly greater in weight than Lake Huron female walleye $(t=28.74 ; \mathrm{df}=10 ; P<$ 469 0.0001). Likewise, Lake Erie male walleye at a given age were significantly greater in weight 470 than Lake Huron male walleye $(t=56.74 ; \mathrm{df}=10 ; P<0.0001)$. At a given age, female walleye 471 were significantly greater in weight than male walleye in both Lake Huron $(t=5.56$; $\mathrm{df}=10 ; P=$ $4720.0002)$ and Lake Erie $(t=9.45 ; \mathrm{df}=10 ; P<0.0001)$.

\section{Bioenergetics modeling: fit to observed growth}

475 On average, the rate of food consumption by Lake Erie walleye was nearly double the rate of 476 food consumption by Lake Huron walleye (Fig. 4). At age 13, cumulative consumption by 477 female and male walleye from Lake Erie was 59.9 and $32.4 \mathrm{~kg}$, respectively. In contrast, 478 cumulative consumption at age 13 by female and male walleye from Lake Huron ranged from $47932.0 \mathrm{~kg}$ and $17.2 \mathrm{~kg}$, respectively, in northern Lake Huron to $42.5 \mathrm{~kg}$ and $23.5 \mathrm{~kg}$, respectively, 480 in Saginaw Bay (Fig. 4). Thus, cumulative consumption at age 13 in Saginaw Bay was roughly $48130 \%$ greater than cumulative consumption in the main basin of Lake Huron. Averaging 482 cumulative consumption across ages 4-13, mean cumulative consumption for Lake Erie walleye 
483 was greater than that for Lake Huron (averaging across the three geographic areas) by factors of

4842.0 and 1.8 for females and males, respectively.

485 On average, the rate of food consumption by female walleye exceeded the rate of food

486 consumption by male walleye by a factor of 1.6 (Fig. 4). Averaging cumulative consumption

487 across ages $4-13$, mean cumulative consumption by females was greater than that by males by

488 factors of 1.6, 1.6, 1.6, and 1.7 for northern Lake Huron, southern Lake Huron, Saginaw Bay, 489 and Lake Erie, respectively.

\section{Bioenergetics modeling: exchanging temperature regimes between areas and sexes}

493 regimes between geographical areas did not exceed $16 \%$ for female walleye and did not exceed $49429 \%$ for male walleye (Figs. 5-8). For northern Lake Huron, weight at age for female and male 495 walleye decreased, on average, by $15 \%$ and $26 \%$, respectively, when the Lake Erie temperature 496 regimes were imposed (Fig. 5). In contrast, weight at age decreased, on average, by only 5\% for 497 both female and male walleye when the southern Lake Huron temperature regimes were imposed 498 in northern Lake Huron. For southern Lake Huron, weight at age for female and male walleye 499 decreased, on average, by $11 \%$ and $23 \%$, respectively, when the Lake Erie temperature regimes 500 were imposed (Fig. 6). However, weight at age increased by 5\%, on average, for both female 501 and male walleye when the northern Lake Huron temperatures were imposed in southern Lake 502 Huron. For Saginaw Bay, weight at age of female and male walleye increased, on average, by $503 \quad 16 \%$ and 21\% when northern Lake Huron temperatures were imposed (Fig. 7). When Lake Erie 504 temperatures were imposed in Saginaw Bay, weight at age of female and male walleye 505 decreased, on average, by $<1 \%$ and $10 \%$, respectively. For Lake Erie, weight at age of female 
506 and male walleye increased, on average, by $14 \%$ and $29 \%$, respectively, when northern Lake

507 Huron temperatures were used in the bioenergetics model simulations (Fig. 8). In contrast,

508 weight at age of female and male walleye increased, on average, by only $1 \%$ and $9 \%$,

509 respectively, when the Saginaw Bay temperature regimes were imposed.

510 Changes in walleye weight at age were less than $7 \%$ when temperature regimes were

511 exchanged between sexes in the bioenergetics model simulations (Fig. 9). For northern Lake

512 Huron, weight at age of females increased by $1 \%$, on average, while weight at age of males

513 decreased by $2 \%$, on, average, when temperature regimes were exchanged between the sexes.

514 For southern Lake Huron, weight at age of females increased by $3 \%$, on average, while weight at

515 age of males decreased by $3 \%$, on average, when temperatures were swapped between the sexes.

516 For Saginaw Bay, weight at age of females increased by $3 \%$, on average, whereas weight at age

517 of males decreased by $3 \%$, on average, when temperatures were exchanged between the sexes

518 (Fig. 9). Finally, for Lake Erie, weight at age of females decreased by 3\%, on average, while

519 weight at age of males increased by $5 \%$, on average, when temperature regimes were exchanged

520 between the sexes.

\section{Discussion}

523 The observed difference in temperature regimes experienced by walleye between the two

524 lakes made no contribution whatsoever toward the faster walleye growth in Lake Erie compared

525 with Lake Huron. Data from our iButton temperature loggers implanted in fish indicated that

526 Lake Erie walleye experienced higher temperatures than Lake Huron walleye. Thus, if food

527 availability, as indexed by food consumption, did not differ between the two lakes and all other

528 factors (factors other than temperature regime) affecting growth were identical between the two 
529 lakes, then walleye growth would have been expected to be faster in Lake Huron than in Lake

530 Erie. Moreover, results from our bioenergetics model simulations showed that walleye growth in

531 Lake Huron would decrease if Lake Erie temperature regimes were imposed in Lake Huron, and

532 that walleye growth in Lake Erie would increase if Lake Huron temperature regimes were

533 imposed in Lake Erie.

534 We conclude that faster walleye growth in Lake Erie compared with walleye growth in Lake

535 Huron was most likely due to much greater food availability in Lake Erie compared with that in

536 Lake Huron. This conclusion was supported by the available data from prey fish hydroacoustics

537 surveys from both lakes. Lakewide mean pelagic prey fish biomass density in Lake Huron was

538 about $8 \mathrm{~kg} /$ ha during 2011-2012, based on results from the lakewide hydroacoustics survey

539 (Warner et al. 2013). The dominant pelagic prey fish species in Lake Huron included rainbow

540 smelt and bloater (Coregonus hoyi), and each species contributed approximately 50\% to the

541 overall biomass density. In contrast to Lake Huron, acoustic estimates of mean biomass density

542 of yearling and older rainbow smelt in central and eastern Lake Erie during 2011-2012 ranged

543 from 69 to 85 kg/ha (Forage Task Group 2012, 2013; Patrick Kocovsky, US Geological Survey,

544 Great Lakes Science Center, personal communication). Our conclusion was also supported by

545 the available data on lake primary production. Estimates of annual primary production in Lake

546 Erie and Lake Huron during 2008, the only recent year for which these estimates were available,

547 were $5.4 \mathrm{kt} \mathrm{C} / \mathrm{ha}$ and $0.8 \mathrm{kt} \mathrm{C} /$ ha, respectively, where $1 \mathrm{kt} \mathrm{C}=1$ kilotonne $\mathrm{C}=1000$ metric tons

548 of carbon fixed by photosynthesis during the year (Great Lakes Primary Production Model

549 2017). Thus, from a primary production standpoint, Lake Erie had potential to support a

550 substantially higher prey fish biomass density than Lake Huron. 
The higher food availability in Lake Erie compared with Lake Huron was not due to the

552 biomass density of walleye in Lake Huron being substantially greater than that in Lake Erie. As

553 density of a fish population increases, intraspecific competition for food within the fish

554 population is expected to increase, and consequently growth of individual fish within the 555 population would be expected to decrease (Lorenzen and Enberg 2002). Thus, as biomass

556 density of the fish population increases, availability of food for an individual fish in the

557 population tends to decrease, and growth of individual fish tends to decrease as well. Adult

558 walleye population biomass in Saginaw Bay and the main basin of Lake Huron averaged 1.6 kt

559 during 2011-2012 (Fielder and Bence 2014). Assuming that the bulk of the walleye population

560 in the main basin of Lake Huron inhabits waters corresponding to bottom depths less than $23 \mathrm{~m}$

561 deep, and including all of Saginaw Bay as habitable by walleye, the surface area available to

562 walleye in the main basin of Lake Huron and Saginaw Bay would be $7057 \mathrm{~km}^{2}$ (Wang et al.

563 2015). This assumption appeared to be a reasonable one (Fielder and Bence 2014). Thus, adult

564 walleye biomass density in the habitable region of Lake Huron's main basin and Saginaw Bay

565 was estimated to be $2 \mathrm{~kg} / \mathrm{ha}$. Adult walleye population biomass in Lake Erie averaged $65.4 \mathrm{kt}$

566 during 2011-2012 (Walleye Task Group 2016), and all of Lake Erie's surface area of $25690 \mathrm{~km}^{2}$

567 was considered habitable by walleye (Ryan et al. 2003; Pandit et al. 2013). Thus, adult walleye

568 biomass density in Lake Erie was estimated to be $25 \mathrm{~kg} / \mathrm{ha}$, a value more than an order of

569 magnitude higher than that for Lake Huron. Clearly, the higher food availability in Lake Erie

570 was not attributable to greater adult walleye biomass density in Lake Huron compared with that

571 for Lake Huron.

572 We also conclude that food availability was of considerably more importance in determining

573 walleye growth in the Lake Huron - Lake Erie system than temperature regime. The faster 
574 walleye growth in Lake Erie than in Lake Huron was solely attributable to greater food

575 availability in Lake Erie than in Lake Huron. On average, Lake Erie walleye grew 85\% faster

576 than Lake Huron walleye. Our bioenergetics modeling results indicated that variability in

577 temperature regimes among geographic areas of the Lake Huron - Lake Erie system could

578 account for up to a $16 \%$ change in the growth of female walleye and a $29 \%$ change in the growth

579 of male walleye. More specifically, we showed that variation in temperature regimes between

580 the three basins of Lake Huron could account for as high as a $16 \%$ change in growth of female

581 walleye and as high as a $21 \%$ change in growth of male walleye. In addition, variation in

582 temperature regimes between the two lakes could account for as high as a $15 \%$ change in growth

583 of female walleye and as high as a $29 \%$ change in growth of male walleye. Clearly, of these two

584 factors affecting walleye growth, food availability was the dominant factor in the Lake Huron -

585 Lake Erie system.

586 The faster walleye growth in Lake Erie compared with that in Lake Huron was not explained

587 by differences in prey and/or walleye energy densities between the two lakes. If the ratio of

588 walleye energy density to prey energy density was greater for Lake Huron than for Lake Erie,

589 then walleye would have to consume more food in Lake Huron than in Lake Erie to achieve the

590 same amount of growth, all other factors being equal. Thus, this scenario would contribute

591 toward faster walleye growth in Lake Erie than in Lake Huron. However, the ratio of walleye

592 energy density to prey energy density for Lake Erie was greater than that for Lake Huron.

593 Averaging across ages 3-13, walleye energy densities were 6311 and $8288 \mathrm{~J} / \mathrm{g}$ in Lake Huron and

594 Lake Erie, respectively. Weighted (weighting by the proportion of each prey type eaten)

595 averages of prey energy densities were 4888, 4251, and $5350 \mathrm{~J} / \mathrm{g}$ in the main basin of Lake

596 Huron, Saginaw Bay, and Lake Erie, respectively. Consequently, values of the ratio of walleye 
597 energy density to prey energy density were $1.29,1.48$, and 1.55 for the main basin of Lake 598 Huron, Saginaw Bay, and Lake Erie, respectively. Thus, Lake Erie walleye had to consume 599 more food than Lake Huron walleye to achieve the same amount of growth, all other factors

600 being equal. And Lake Erie walleye grew nearly twice as fast as Lake Huron walleye. In sum, 601 differences in walleye and prey energy densities between the two lakes did not contribute toward 602 the faster walleye growth in Lake Erie.

603 Our research has provided new insights into the effect of variation in temperature regimes 604 between the sexes on the difference in walleye growth between the sexes. For all three basins of 605 Lake Huron, females experienced slightly higher temperatures, on average, than males.

606 Exchanging temperature regimes between the sexes of Lake Huron walleye resulted in slight (< $6075 \%$ ) increases in growth of females and slight decreases in growth of males. Thus, sex 608 differences in temperature regimes could not account for any portion of the observed difference 609 in growth between the sexes of Lake Huron walleye, as observed weight at age of females 610 averaged $47 \%$ higher than that of males over ages 3-13. For Lake Erie, males experienced 611 slightly higher temperatures than females. Exchanging temperature regimes between the sexes 612 of Lake Erie walleye led to a 3\% decrease, on average, in growth of females and a 5\% increase, 613 on average, in growth of males. Thus, the sex difference in temperature regimes could account 614 for females being about $8 \%$ greater in weight at age than males from Lake Erie. Females were 615 observed to be $56 \%$ greater, on average, in weight at age than males from Lake Erie. We 616 conclude that the sex difference in temperature regimes explained $15 \%$ of the observed 617 difference in growth between the sexes of Lake Erie walleye, but none of the observed sex 618 difference in growth of Lake Huron walleye. More research is needed to identify the 619 predominant causes underlying sexually dimorphic growth in fish. We also note that the slightly 
620 higher temperature regime experienced by male walleye compared with female walleye in Lake

621 Erie was expected based on results reported by Wang et al. (2007). Using data from a long-term

622 mark and recapture study, these researchers showed that male walleye were more likely to reside

623 in the western basin of Lake Erie throughout the year than female walleye. On average, surface

624 water temperatures in the western basin are higher than those in the central or eastern basin of

625 Lake Erie (Moukomla and Blanken 2016), and therefore higher temperatures experienced by

626 males would be presumed. Reasons for the slightly higher temperatures experienced by females

627 compared with males in Lake Huron were unclear.

628 One caveat for our findings was that the growth trajectories that we developed for walleye

629 from Lake Huron were specifically for the Saginaw Bay walleye stock, which inhabits Saginaw

630 Bay and the main basin of Lake Huron (Fielder and Bence 2014; Hayden et al. 2014). Walleye

631 stocks also inhabit both Georgian Bay and the North Channel of Lake Huron, but these walleye

632 stocks do not mix with the Saginaw Bay stock (Fielder et al. 2010; Stepien et al. 2010). Walleye

633 grew faster in Georgian Bay and the North Channel than in the main basin of Lake Huron during

634 1982-2003 (Chu and Koops 2007), and this difference in growth appears to hold true today as

635 well (Arunas Liskauskas and Adam Cottrill, Ontario Ministry of Natural Resources and Forestry, 636 personal communication).

637 Another caveat for our findings was that the temperature regimes that we developed for

638 walleye residing in the main basin of Lake Huron were based on relatively low numbers of

639 recaptured walleye. Temperature regimes for the northern main basin of Lake Huron were based

640 on data from 5 females and 3 males, and temperature regimes for the southern main basin of

641 Lake Huron were based on data from 7 females and 2 males. However, despite the low sample

642 sizes with regard to number of walleye recaptured, the temperature regimes did indeed show that 
643 walleye experienced slightly higher temperatures in the southern main basin than in the northern

644 main basin and that walleye experienced higher temperatures in Saginaw Bay than in the main

645 basin of Lake Huron, as would be expected based on the long-term observations of surface water

646 temperatures by Moukomla and Blanken (2016). To perform a bioenergetics analysis for

647 walleye growth in Georgian Bay and the North Channel of Lake Huron analogous to that from

648 our study, temperature regimes for Georgian Bay walleye and North Channel walleye would

649 need to be developed. This would involve implanting Georgian Bay walleye and North Channel

650 walleye with temperature loggers.

651 Our results should be useful in refining and updating models for quantifying the role of 652 walleye as a piscivore in the Lake Huron and Lake Erie ecosystems. He et al. (2015) coupled

653 age-structured population models with fish bioenergetics models to assess the effect of piscivory 654 by Chinook salmon (Oncorhynchus tshawytscha), lake trout (Salvelinus namaycush), walleye, 655 and lake whitefish (Coregonus clupeaformis) on Lake Huron prey fish populations. For 656 modeling purposes, these researchers assumed that the temperature regime experienced by 657 walleye was equivalent to the long-term mean temperature profile from daily water temperature 658 records kept at the Bay Metro Water Treatment Plant, which drew water directly from Saginaw 659 Bay. Their modeling effort could be refined and updated by applying the temperature regimes 660 developed in our study based on data from iButton temperature loggers implanted in Lake Huron 661 walleye. With regard to assessing the role of piscivory by the Lake Erie walleye population on 662 prey fish populations, previous efforts have relied on temperature regimes derived from 663 measurements of water temperatures in Lake Erie (Hartman and Margraf 1992; Kershner et al. 664 1999), rather than derived from in situ measurements from temperature loggers implanted in 665 Lake Erie walleye. Application of our temperature regimes based on data from the iButton 
666 temperature loggers would lead to more accurate estimates of prey fish consumption by the Lake

667 Erie walleye population. Moreover, the two above-mentioned bioenergetics model applications

668 to the Lake Erie walleye population were not based on energy density determinations specifically

669 for Lake Erie walleye. Rather, energy density of Lake Erie walleye was assumed to equal that of

670 a typical value for fishes (Winberg 1956; Hewett and Johnson 1992). Use of our energy density

671 determinations specifically for Lake Erie walleye would improve the accuracy of the

672 bioenergetics model applications to the Lake Erie walleye population. Finally, detailed studies

673 on walleye diet in Lake Erie, like the studies conducted during the late 1970s and 1980s (Knight

674 et al. 1984; Hartman and Margraf 1992), have rarely been published since 1995. Our study

675 provided a detailed diet schedule for Lake Erie walleye, from spring through fall based on more

676 than 3000 non-empty stomachs, by summarizing stomach contents data over years 2000-2015.

677 This diet schedule will be invaluable in updating and refining models used to quantify the effects

678 of piscivory by the Lake Erie walleye population on Lake Erie prey fish populations. Once the

679 models for quantifying piscivory by the walleye population have been refined, these new models

680 would contribute toward ecosystem-based management, as advocated by Link (2002), Pikitch et

681 al. (2004), Tsehaye et al. (2014), and Grüss et al. (2017), of the important fisheries operating in

682 both lakes.

683 Our study was innovative, from two perspectives. First, our study represented the first 684 assessment of the effect of a sex difference in temperature regimes on the sex difference in 685 growth within a fish population. We found that the sex difference in temperature regimes for

686 Lake Huron walleye made no contribution at all to the observed faster growth of females 687 compared with males. In the case of Lake Erie walleye, the sex difference in temperature 688 regimes accounted for $15 \%$ of the observed difference in growth between the sexes. Thus, 
689 although the sex difference in temperature regimes contributed to the observed sex difference in

690 growth of Lake Erie walleye, it was not the primary driver of the sexually dimorphic walleye

691 growth. Second, we were the first to evaluate the effects of both interbasin and interlake

692 variability in temperature regimes on fish growth in a two-lake system with a waterway

693 connection between the two lakes. Results showed that interbasin and interlake variability in

694 temperature regimes had just a moderate effect on walleye growth in the Lake Huron - Lake Erie

695 system. Further, food availability was the dominant factor affecting walleye growth in this two-

696 lake system. Coupling of archival temperature tagging and acoustic telemetry with fish

697 bioenergetics modeling should continue to provide new insights into the relative importance of

698 temperature regime as a factor influencing fish growth in fish populations from multi-lake

699 systems around the world.

700

\section{Acknowledgements}

702 The authors would like to convey our appreciation to the staffs at the Sandusky and Fairport 703 Harbor Fisheries Research Stations (Ohio DNR), Lake Erie Management Unit (OMNRF),

704 Waterford Fisheries Station - West (Michigan DNR), Lake Erie and Hammond Bay Biological

705 Stations (US Geological Survey Great Lakes Science Center), and Lower Great Lakes Fish and

706 Wildlife Conservation Office (US Fish and Wildlife Service) for maintaining the acoustic

707 receiver network throughout the duration of the study. We are specifically grateful to K.

708 Murchie (Carleton University), J. Ives (Great Lakes Fishery Commission), and S. Zahn Seegert

709 (Great Lakes Fishery Commission) for their assistance in the field implanting of acoustic

710 transmitters, to C. Holbrook (Hammond Bay Biological Station) for providing study design

711 recommendations, and to the staff at the Fairport Harbor Fisheries Research Station for 
712 maintaining the Lake Erie walleye diet database. We are also grateful to the Great Lakes Fishery

713 Commission for distributing rewards for captured walleye implanted with temperature loggers.

714 We thank Danielle Forsythe for her assistance with calculation of lake surface areas. Use of

715 trade, product, or firm names does not imply endorsement by the United States Government.

716 This work was funded by the Great Lakes Fishery Commission by way of Great Lakes Research

717 Initiative appropriations (GL-00E23010) to CCK. This article is Contribution 33 of the Great

718 Lakes Acoustic Telemetry Observation System (GLATOS).

\section{References}

721 Bergstedt, R.A., Argyle, R.L., Seelye, J.G., Scribner, K.T., and Curtis, G.L. 2003. In situ 722 determination of the annual thermal habitat use by lake trout (Salvelinus namaycush) in 723 Lake Huron. J. Gt. Lakes Res. 29(Suppl. 1): 347-361.

724 Bozek, M.A., Baccante, D.A., and Lester, N.P. 2011. Walleye and sauger life history. In 725 Biology, management, and culture of walleye and sauger. Edited by B.A. Barton. American 726 Fisheries Society, Bethesda. pp. 233-301.

727 Bunnell, D.B., Johnson, T.B., and Knight, C.T. 2005. The impact of introduced round gobies 728 (Neogobius melanostomus) on phosphorus cycling in central Lake Erie. Can. J. Fish. Aquat. $729 \quad$ Sci. 62: 15-29.

730 Chipps, S.R., and Wahl, D.H. 2008. Bioenergetics modeling in the 21 st century: reviewing new 731 insights and revisiting old constraints. Trans. Am. Fish. Soc. 137: 298-313.

732 Chu, C., and Koops, M.A. 2007. Life history parameters of Great Lakes populations of lake 733 trout, lake whitefish, bloater, walleye, and yellow perch. Can. Manuscr. Rep. Fish. Aquat. 734 Sci. 2811. 
735 Cooke, S.J., Midwood, J.D., Thiem, J.D., Klimley, P., Lucas, M.C., Thorstad, E.B., Eiler, J.,

736 Holbrook, C., and Ebner, B.C. 2013. Tracking animals in freshwater with electronic tags:

737 past, present and future. Anim. Biotelem. 1: 5.

738 Cummins, K.W., and Wuycheck, J.C. 1971. Caloric equivalents for investigations in ecological 739 energetics. Mitt. Int. Ver. Theor. Angew. Limnol. 18: 1-151.

740 Deslauriers, D., Chipps, S.R., Breck, J.E., Rice, J.A., and Madenjian, C.P. 2017. Fish

741 Bioenergetics 4.0: An R-based modeling application. Fisheries 42: 586-596.

742 Donaldson, M.R., Cooke, S.J., Patterson, D.A., Hinch, S.C., Robichaud, D., Hanson, K.C.,

743 Olsson, I., Crossin, G.T., English, K.K., and Farrell, A.P. 2009. Limited behavioural

744 thermoregulation by adult upriver-migrating sockeye salmon (Oncorhynchus nerka) in the

745 Lower Fraser River, British Columbia. Can. J. Zool. 87: 480-490.

746 Enberg, K., Dunlop, E.S., and Jørgensen, C. 2008. Fish growth. In Encyclopedia of ecology.

747 Edited by S.E. Jørgensen and B.D. Fath. Elsevier, Oxford. pp. 1564-1572.

748 Feiner, Z.S., and Höök, T.O. 2015. Environmental biology of percid fishes. In Biology and

749 culture of percid fishes: principles and practices. Edited by P. Kestemont, K. Dabrowski,

750 and R.C. Summerfelt. Springer, Dordrecht. pp. 61-100.

751 Fielder, D.G. 2014. Mortality, exploitation, movement, and stock size of Saginaw Bay

752 Walleyes, 1981-2011: 31 years of tag return analysis. Michigan Department of Natural

753 Resources, Fisheries Report 04, Lansing, Mich.

754 Fielder, D.G., and Bence, J.R. 2014. Integration of auxiliary information in statistical catch-at755 age (SCA) analysis of the Saginaw Bay stock of Walleye in Lake Huron. N. Am. J. Fish.

$756 \quad$ Manage. 34: 970-987. 
757 Fielder, D.G., and Thomas, M.V. 2014. Status and trends of the fish community of Saginaw 758 Bay, Lake Huron 2005-2011. Michigan Department of Natural Resources, Fisheries Report 759 03, Lansing, Mich.

760 Fielder, D.G., Liskauskas, A.P., Gonder, D.J.A., Mohr, L.C., and Thomas, M.V. 2010. Status of 761 walleye in Lake Huron. In Status of walleye in the Great Lakes: proceedings of the 2006 762 Symposium. Great Lakes Fish. Comm. Tech. Rep. 69. pp. 71-90.

763 Fielder, D.G., Kolb, T.L., Goniea, T.M., Wesander, D.L., and Schrouder, K.S. 2014. Fisheries 764 of Saginaw Bay, Lake Huron 1986-2010. Michigan Department of Natural Resources, 765 Fisheries Report 02, Lansing, Mich.

766 Forage Task Group. 2012. Report of the Lake Erie Forage Task Group to the Standing 767 Technical Committee of the Lake Erie Committee, Great Lakes Fishery Commission, Ann 768 Arbor, Mich. Available from:

769 http://www.glfc.org/lakecom/lec/FTG_docs/annual_reports/FTG_report_2012.pdf. $770 \quad$ [accessed 1 June 2017].

771 Forage Task Group. 2013. Report of the Lake Erie Forage Task Group to the Standing 772 Technical Committee of the Lake Erie Committee, Great Lakes Fishery Commission, Ann 773 Arbor, Mich. Available from:

774 http://www.glfc.org/lakecom/lec/FTG_docs/annual_reports/FTG_report 2013.pdf. $775 \quad$ [accessed 1 June 2017].

776 Great Lakes Information Network. 2017. Great Lakes Commission, Ann Arbor, Mich.

777 Available from: http://maps.glin.net. [accessed 1 December 2017]. 
778 Great Lakes Primary Production Model. 2017. Michigan Tech Research Institute, Michigan

779 Technological University, Ann Arbor, Mich. Available from:

780 http://www.mtri.org/glppm.html. [accessed 1 June 2017].

781 Grüss, A., Rose, K.A., Simons, J., Ainsworth, C.H., Babcock, E.A., Chagaris, D.D., De Mutsert,

782 K., Froeschke, J., Himchak, P., Kaplan, I.C., O’Farrell, H., and Zetina Rejon, M.J. 2017.

783 Recommendations on the use of ecosystem modeling for informing ecosystem-based

784 fisheries management and restoration outcomes in the Gulf of Mexico. Mar. Coast. Fish. 9:

$785 \quad 281-295$.

786 Hartman, K.J., and Margraf, F.J. 1992. Effects of prey and predator abundances on prey

787 consumption and growth of walleyes in western Lake Erie. Trans. Am. Fish. Soc. 121: 245-

$788 \quad 260$.

789 Hayden, T.A., Holbrook, C.M., Fielder, D.G., Vandergoot, C.S., Bergstedt, R.A., Dettmers, J.M.,

790 Krueger, C.C., and Cooke, S.J. 2014. Acoustic telemetry reveals large-scale migration

791 patterns of walleye in Lake Huron. PLoS ONE 9: e11833.

792 Hayward, R.S., and Margraf, F.J. 1987. Eutrophication effects on prey size and food available

793 to yellow perch in Lake Erie. Trans. Am. Fish. Soc. 116: 210-223.

794 He, J.X., Bence, J.R., Madenjian, C.P., Pothoven, S.A., Dobiesz, N.E., Fielder, D.G., Johnson,

795 J.E., Ebener, M.P., Cottrill, R.A., Mohr, L.C., and Koproski, S.R. 2015. Coupling age-

796 structured stock assessment and fish bioenergetics models: a system of time-varying models

797 for quantifying piscivory patterns during the rapid trophic shift in the main basin of Lake

798 Huron. Can. J. Fish. Aquat. Sci. 72: 7-23. 
Hewett, S.W., and Johnson, B.L. 1992. Fish bioenergetics model 2: an upgrade of a generalized bioenergetics model of fish growth for microcomputers. University of Wisconsin Sea Grant Institute, Technical Report WIS-SG-92-250, Madison, Wisc.

Jobling, M. 1994. Fish bioenergetics. Chapman and Hall, London.

Kao, Y.-C., Madenjian, C.P., Bunnell, D.B., Lofgren, B.M., and Perroud, M. 2015a. salmonines in Lakes Michigan and Huron. Environ. Biol. Fishes 98: 1089-1104.

Kao, Y.-C., Madenjian, C.P., Bunnell, D.B., Lofgren, B.M., and Perroud, M. 2015b. Potential effects of climate change on the growth of fishes from different thermal guilds in Lakes Michigan and Huron. J. Gt. Lakes Res. 41: 423-435.

Kershner, M.W. 1996. Walleye predatory demand and prey supply in Lake Erie: exploring environmental variation and its historical effects. Ph.D. Dissertation, Ohio State University, Columbus, Ohio.

Kershner, M.W., Schael, D.M., Knight, R.L., Stein, R.A., and Marschall, E.A. 1999. Modeling sources of variation for growth and predatory demand of Lake Erie walleye (Stizostedion vitreum), 1986-1995. Can. J. Fish. Aquat. Sci. 56: 527-538.

Kitchell, J.F., Stewart, D.J., and Weininger, D. 1977. Applications of a bioenergetics model to yellow perch (Perca flavescens) and walleye (Stizostedion vitreum vitreum). J. Fish. Res. Board Can. 34: 1922-1935.

Knight, R.L., Margraf, F.J., and Carline, R.F. 1984. Piscivory by walleyes and yellow perch in western Lake Erie. Trans. Am. Fish. Soc. 113: 677-693.

Landsman, S.J., Nguyen, V.M., Gutowsky, L.F.G., Gobin, J., Cook, K.V., Binder, T.R., Lower, N., McLaughlin, R.L., and Cooke, S.J. 2011. Fish movement and migration studies in the 

Laurentian Great Lakes: Research trends and knowledge gaps. J. Gt. Lakes Res. 37: 365379.

824 Link, J.S. 2002. What does ecosystem-based fisheries management mean? Fisheries 27(4): 1882521.

826 Lorenzen, K., and Enberg, K. 2002. Density-dependent growth as a key mechanism in the 827 regulation of fish populations: evidence from among-population comparisons. Proc. R. Soc. $828 \quad$ Lond. B Biol. Sci. 269: 49-54.

829 Lucas, M.C., and Baras, E. 2000. Methods for studying spatial behavior of freshwater fishes in 830 the natural environment. Fish Fish. 1: 283-316.

831 Madenjian, C.P. 2011. Bioenergetics in ecosystems. In Encyclopedia of fish physiology: from 832 genome to environment. Edited by A.P. Farrell. Academic Press, San Diego. pp. 1675$833 \quad 1680$.

834 Madenjian, C.P., Noguchi, G.E., Haas, R.C., and Schrouder, K.S. 1998. Sexual difference in 835 polychlorinated biphenyl accumulation rates of walleye (Stizostedion vitreum). Can. J. Fish. 836 Aquat. Sci. 55: 1085-1092.

837 Madenjian, C.P., Cochran, P.A., and Bergstedt, R.A. 2003. Seasonal patterns in growth, blood 838 consumption, and effects on hosts by parasitic-phase sea lampreys in the Great Lakes: an 839 individual-based model approach. J. Gt. Lakes Res. 29(Suppl. 1): 332-346.

840 Madenjian, C.P., O’Connor, D.V., Pothoven, S.A., Schneeberger, P.J., Rediske, R.R., O’Keefe, 841 J.P., Bergstedt, R.A., Argyle, R.L., and Brandt, S.B. 2006. Evaluation of a lake whitefish 842 bioenergetics model. Trans. Am. Fish. Soc. 135: 61-75.

843 Melstrom, R.T., and Lupi, F. 2013. Valuing recreational fishing in the Great Lakes. N. Am. J. $844 \quad$ Fish. Manage. 33: 1184-1193. 
845 Moukomla, S., and Blanken, P.D. 2016. Remote sensing of the North American Laurentian $846 \quad$ Great Lakes's surface temperature. Remote Sens. 8: 286.

847 Ogle, D.H. 2016. FSA: Fisheries Stock Analysis. R package version 0.8.11.

848 Ohio Division of Wildlife. 2011. Ohio’s Lake Erie fisheries, 2010. Annual status report.

849 Federal Aid in Fish Restoration Project F-69-P. Ohio Department of Natural Resources,

850 Division of Wildlife, Lake Erie Fisheries Units, Fairport and Sandusky, Ohio.

851 Ohio Division of Wildlife. 2012. Ohio's Lake Erie fisheries, 2011. Annual status report.

852 Federal Aid in Fish Restoration Project F-69-P. Ohio Department of Natural Resources,

853 Division of Wildlife, Lake Erie Fisheries Units, Fairport and Sandusky, Ohio.

854 Ohio Division of Wildlife. 2013. Ohio’s Lake Erie fisheries, 2012. Annual status report.

855 Federal Aid in Fish Restoration Project F-69-P. Ohio Department of Natural Resources,

856 Division of Wildlife, Lake Erie Fisheries Units, Fairport and Sandusky, Ohio.

857 Ohio Division of Wildlife. 2016. Ohio's Lake Erie fisheries, 2015. Annual status report.

858 Federal Aid in Fish Restoration Project F-69-P. Ohio Department of Natural Resources,

859 Division of Wildlife, Lake Erie Fisheries Units, Fairport and Sandusky, Ohio.

860 Pandit, S.N., Zhao, Y., Ciborowski, J.J.H., Gorman, A., and Knight, C.T. 2013. Suitable habitat 861 model for walleye (Sander vitreus) in Lake Erie: Implications for inter-jurisdictional harvest 862 quota allocations. J. Gt. Lakes Res. 39: 591-601.

863 Peat, T.B., Hayden, T.A., Gutowsky, L.F.G., Vandergoot, C.S., Fielder, D.G., Madenjian, C.P., 864 Murchie, K.J., Dettmers, J.M., Krueger, C.C., and Cooke, S.J. 2015. Seasonal thermal 865 ecology of adult walleye (Sander vitreus) in Lake Huron and Lake Erie. J. Therm. Biol. 53: $86698-106$. 
867 Persson, L., and Greenberg, L.A. 1990. Juvenile competitive bottlenecks: the perch (Perca 868 fluviatilis)-roach (Rutilus rutilus) interaction. Ecology 71: 44-56.

869 Pikitch, E.K., Santora, C., Babcock, E.A., Bakun, A., Bonfil, R., Conover, D.O., Dayton, P., 870 Doukakis, P., Fluharty, D., Heneman, B., Houde, E.D., Link, J., Livingston, P.A., Mangel, 871 M., McAllister, M.K., Pope, J., and Sainsbury, K.J. 2004. Ecosystem-based fishery 872 management. Science 305: 346-347.

873 Pincock, D.G. 2009. Detection performance of lines of VR2W/VR3 receivers. Available from: 874 http://vemco.com/vp-content/uploads/2012/11/line performance.pdf. [accessed 1 June 875 2017].

876 Pothoven, S.A., Ludsin, S.A., Höök, T.O., Fanslow, D.L., Mason, D.M., Collingsworth, P.D., 877 and Van Tassell, J.J. 2008. Reliability of bioelectrical impedance analysis for estimating 878 whole-fish energy density and percent lipids. Trans. Am. Fish. Soc. 137: 1519-1529.

879 Pothoven, S.A., Bunnell, D.B., Madenjian, C.P., Gorman, O.T., and Roseman, E.F. 2012. 880 Energy density of bloaters in the Upper Great Lakes. Trans. Am. Fish. Soc. 141: 772-780. 881 Pothoven, S.A., Madenjian, C.P., and Höök, T.O. 2017. Feeding ecology of the walleye 882 (Percidae, Sander vitreus), a resurgent piscivore in Lake Huron (Laurentian Great Lakes) 883 after shifts in the prey community. Ecol. Freshw. Fish 26: 676-685.

884 Quinn, T.J., II, Deriso, R.B. 1999. Quantitative fish dynamics. Oxford University Press, New $885 \quad$ York.

886 Rennie, M.D., and Venturelli, P.A. 2015. The ecology of lifetime growth in percid fishes. In 887 Biology and culture of percid fishes: principles and practices. Edited by P. Kestemont, K. 888 Dabrowski, and R.C. Summerfelt. Springer, Dordrecht. pp. 499-536. 
Roseman, E.F., Knight, R.L., Wright, E., Einhouse, D., Kayle, K., Newman, K., and Hoopes, R.L. 2008. Ecology and international governance of Lake Erie's percid fisheries. In International governance of fisheries ecosystems: learning from the past, finding solutions for the future. Edited by M.G. Schechter, N.J. Leonard, and W.W. Taylor. American Fisheries Society, Bethesda. pp. 145-169.

Ryan, P.A., Knight, R., MacGregor, R., Towns, G., Hoopes, R., and Culligan, W. 2003. Fishcommunity goals and objectives for Lake Erie. Great Lakes Fishery Commission, Special Publication 03-02, Ann Arbor, Mich.

Stepien, C.A., Murphy, D.J., Lohner, R.N., Haponski, A.E., and Sepulveda-Villet, O.J. 2010. Status and delineation of walleye (Sander vitreus) genetic stock structure across the Great Lakes. In Status of walleye in the Great Lakes: proceedings of the 2006 Symposium. Great Lakes Fish. Comm. Tech. Rep. 69. pp. 189-223.

Tsehaye, I., Jones, M.L., Bence, J.R., Brenden, T.O., Madenjian, C.P., and Warner, D.M. 2014. A multispecies statistical age-structured model to assess predator-prey balance: application to an intensively managed Lake Michigan pelagic fish community. Can. J. Fish. Aquat. Sci. 71: 627-644.

Vandergoot, C.S., Murchie, K.J., Cooke, S.J., Dettmers, J.M., Bergstedt, R.A., and Fielder, D.G. 2011. Evaluation of two forms of electroanesthesia and carbon dioxide for short-term anesthesia in walleye. N. Am. J. Fish. Manage. 31: 914-922.

Walleye Task Group. 2016. Report of the Lake Erie Walleye Task Group to the Standing Technical Committee of the Lake Erie Committee, Great Lakes Fishery Commission, Ann Arbor, Mich. Available: 

http://www.glfc.org/lakecom/lec/WTG_docs/annual_reports/WTG_report_2016.pdf.

$912 \quad$ [accessed 1 June 2017].

913 Wang, H.-Y., Rutherford, E.S., Cook, H.A., Einhouse, D.W., Haas, R.C., Johnson, T.B.,

914 Kenyon, R., Locke, B., and Turner, M.W. 2007. Movement of walleyes in Lakes Erie and

915 St. Clair inferred from tag return and fisheries data. Trans. Am. Fish. Soc. 136: 539-551.

916 Wang, H.-Y., Cook, H.A., Einhouse, D.W., Fielder, D.G., Kayle, K.A., Rudstam, L.G., and

917 Höök, T.O. 2009. Maturation schedules of walleye populations in the Great Lakes region:

918 comparison of maturation indices and evaluation of sampling-induced biases. N. Am. J.

$919 \quad$ Fish. Manage. 29: 1540-1554.

920 Wang, L., Riseng, C.M., Mason, L.A., Wehrly, K.E., Rutherford, E.S., McKenna, J.E., Jr, 921 Castiglione, C., Johnson, L.B., Infante, D.M., Sowa, S., Robertson, M., Schaeffer, J., 922 Khoury, M., Gaiot, J., Hollenhorst, T., Brooks, C., and Coscarelli, M. 2015. A spatial 923 classification and database for management, research, and policy making: The Great Lakes 924 aquatic habitat framework. J. Gt. Lakes Res. 41: 584-596.

925 Warner, D.M., O’Brien, T.P., Farha, S., Schaeffer, J.S., and Lenart, S. 2013. Status and trends 926 of pelagic prey fishes in Lake Huron, 2012. U.S. Geological Survey, Great Lakes Science 927 Center, Ann Arbor, Mich. Available from:

928 http://www.glsc.usgs.gov/sites/default/files/product files/Pelagic\%20Preyfish\%20Huron $\% 2$

929 02012.pdf. [accessed 1 June 2017].

930 Werner, E.E. 1974. The fish size, prey size, handling time relation in several sunfishes and 931 some implications. J. Fish. Res. Board Can. 31: 1531-1536.

932 Winberg, G.G. 1956. Rate of metabolism and food requirements of fishes. Fish. Res. Board 933 Can. Transl. Ser. No. 194. 
935

936

Table 1. Diet schedule for adult walleye from Lake Erie.

\begin{tabular}{|c|c|c|c|c|c|c|c|c|}
\hline Month & Shiners & Clupeids & Morone spp. & $\begin{array}{c}\text { Rainbow } \\
\text { smelt }\end{array}$ & $\begin{array}{l}\text { Yellow } \\
\text { perch }\end{array}$ & Round goby & Other fish & Invertebrates \\
\hline April - May & 0.39 & 0.19 & 0.02 & 0.37 & 0.00 & 0.02 & 0.01 & 0.00 \\
\hline June & 0.65 & 0.04 & 0.04 & 0.21 & 0.01 & 0.03 & 0.00 & 0.02 \\
\hline July & 0.47 & 0.00 & 0.00 & 0.34 & 0.08 & 0.08 & 0.00 & 0.03 \\
\hline August & 0.25 & 0.23 & 0.10 & 0.14 & 0.09 & 0.19 & 0.00 & 0.00 \\
\hline September & 0.21 & 0.60 & 0.12 & 0.01 & 0.04 & 0.01 & 0.01 & 0.00 \\
\hline $\begin{array}{l}\text { October - } \\
\text { November }\end{array}$ & 0.19 & 0.74 & 0.01 & 0.06 & 0.00 & 0.00 & 0.00 & 0.00 \\
\hline $\begin{array}{l}\text { December - } \\
\text { March }\end{array}$ & 0.29 & 0.47 & 0.01 & 0.22 & 0.00 & 0.01 & 0.00 & 0.00 \\
\hline
\end{tabular}

Note: Numeric table entries represent estimated proportions in diet, on a wet weight basis. 
940 Table 2. Energy densities for prey of adult walleye from Lake Erie.

941

\begin{tabular}{ccc}
\hline Prey category & Energy density $(\mathrm{J} / \mathrm{g})$ & Source \\
\hline Shiners & 6372 & This study \\
Clupeids & 5014 & Kershner (1996) \\
Morone spp. & 3760 & Kershner (1996) \\
Rainbow smelt & 5241 & This study \\
Yellow perch & 3823 & Kershner (1996) \\
Round goby & 3621 & Bunnell et al. (2005) \\
Other fish & 4512 & Pothoven et al. (2017) \\
Invertebrates & 3134 & Cummins and Wuycheck (1971) \\
\hline
\end{tabular}

942

943

$944 \quad$ Note: Numeric table entries represent energy densities, on a wet weight basis. 
946 Table 3. Parameter estimates from fitting von Bertalanffy growth curves to total length and age

947 data for walleye caught in Saginaw Bay of Lake Huron during September and walleye caught in

948 western and central Lake Erie during October, years 2010-2012.

949

\begin{tabular}{cccc}
\hline Lake and sex & $\mathrm{L}_{\infty}(\mathrm{mm})$ & $\mathrm{K}\left(\mathrm{year}^{-1}\right)$ & $\mathrm{t}_{0}$ (years) \\
\hline Lake Huron females & $629(14)$ & $0.226(0.015)$ & $-0.596(0.125)$ \\
Lake Huron males & $509(5)$ & $0.361(0.017)$ & $-0.079(0.090)$ \\
Lake Erie females & $661(1)$ & $0.374(0.004)$ & $-0.113(0.020)$ \\
Lake Erie males & $558(1)$ & $0.468(0.006)$ & $-0.193(0.025)$ \\
\hline
\end{tabular}

Note: $\mathrm{L}_{\infty}=$ asymptotic average total length, $\mathrm{K}=$ Brody growth coefficient, and $\mathrm{t}_{0}=$ age at

953 which average total length is equal to zero. Standard error enclosed within parentheses. 


\section{Figure captions}

957

958 Fig. 1. Map of study area. Solid circles denote locations for acoustic receivers and solid

959 triangles denote tagging locations. Base map data taken from the Great Lakes Information

960 Network (GLIN) (2017).

961

962 Fig. 2. Temperature regimes experienced by walleye in the northern main basin of Lake Huron, 963 southern main basin of Lake Huron, Saginaw Bay, and Lake Erie, by sex. Each bar represents 964 one standard error. Error bar width may be less than the diameter of the symbol marker used to 965 denote mean temperature, and therefore not visible. See Temperature regimes subsection of 966 Materials and methods section for more details.

967

968 Fig. 3. Growth trajectories for walleye in Lake Huron and Lake Erie, by sex. Estimated weight 969 at age based on gillnet surveys in Saginaw Bay (Lake Huron) during September 2010-2012 and 970 gillnet surveys in Lake Erie during October 2010-2012. Each bar represents one standard error.

971 Error bar width may be less than the diameter of the symbol marker used to denote mean weight 972 at age, and therefore not visible. See Growth trajectories subsection of Materials and methods 973 section for more details.

974

975 Fig. 4. Cumulative food consumption by walleye, beginning at age 3, in the northern main basin 976 of Lake Huron, southern main basin of Lake Huron, Saginaw Bay, and Lake Erie, by sex. Food 977 consumption estimated by application of a walleye bioenergetics model (Kitchell et al. 1977; 
978 Hewett and Johnson 1992) to observed growth trajectories. See Bioenergetics modeling: fit to

979 observed growth subsection of Materials and methods section for more details.

980

981 Fig. 5. Predicted changes in walleye weight at age by replacing the temperature regime

982 experienced by walleye in the northern main basin of Lake Huron with the temperature regime

983 for southern main basin of Lake Huron walleye (upper panel), Saginaw Bay walleye (middle

984 panel), and Lake Erie walleye (lower panel), by sex. See Bioenergetics modeling: exchanging

985 temperature regimes between areas and sexes subsection of the Materials and methods section

986 for more details.

987

988 Fig. 6. Predicted changes in walleye weight at age by replacing the temperature regime

989 experienced by walleye in the southern main basin of Lake Huron with the temperature regime

990 for northern main basin of Lake Huron walleye (upper panel), Saginaw Bay walleye (middle

991 panel), and Lake Erie walleye (lower panel), by sex. See Bioenergetics modeling: exchanging

992 temperature regimes between areas and sexes subsection of the Materials and methods section

993 for more details.

994

995 Fig. 7. Predicted changes in walleye weight at age by replacing the temperature regime

996 experienced by walleye in Saginaw Bay with the temperature regime for walleye from the

997 northern main basin of Lake Huron (upper panel), walleye from the southern main basin of Lake

998 Huron (middle panel), and Lake Erie walleye (lower panel), by sex. See Bioenergetics

999 modeling: exchanging temperature regimes between areas and sexes subsection of the Materials

1000 and methods section for more details. 
1002 Fig. 8. Predicted changes in walleye weight at age by replacing the temperature regime 1003 experienced by walleye in Lake Erie with the temperature regime for walleye from the northern

1004 main basin of Lake Huron (upper panel), walleye from the southern main basin of Lake Huron 1005 (middle panel), and Saginaw Bay walleye (lower panel), by sex. See Bioenergetics modeling: 1006 exchanging temperature regimes between areas and sexes subsection of the Materials and 1007 methods section for more details.

1008

1009 Fig. 9. Predicted changes in walleye weight at age by exchanging temperature regimes 1010 experienced by the walleye between the sexes for each of the four geographic areas: northern 1011 main basin of Lake Huron, southern main basin of Lake Huron, Saginaw Bay, and Lake Erie.

1012 See Bioenergetics modeling: exchanging temperature regimes between areas and sexes 1013 subsection of the Materials and methods section for more details.

1014

1015 


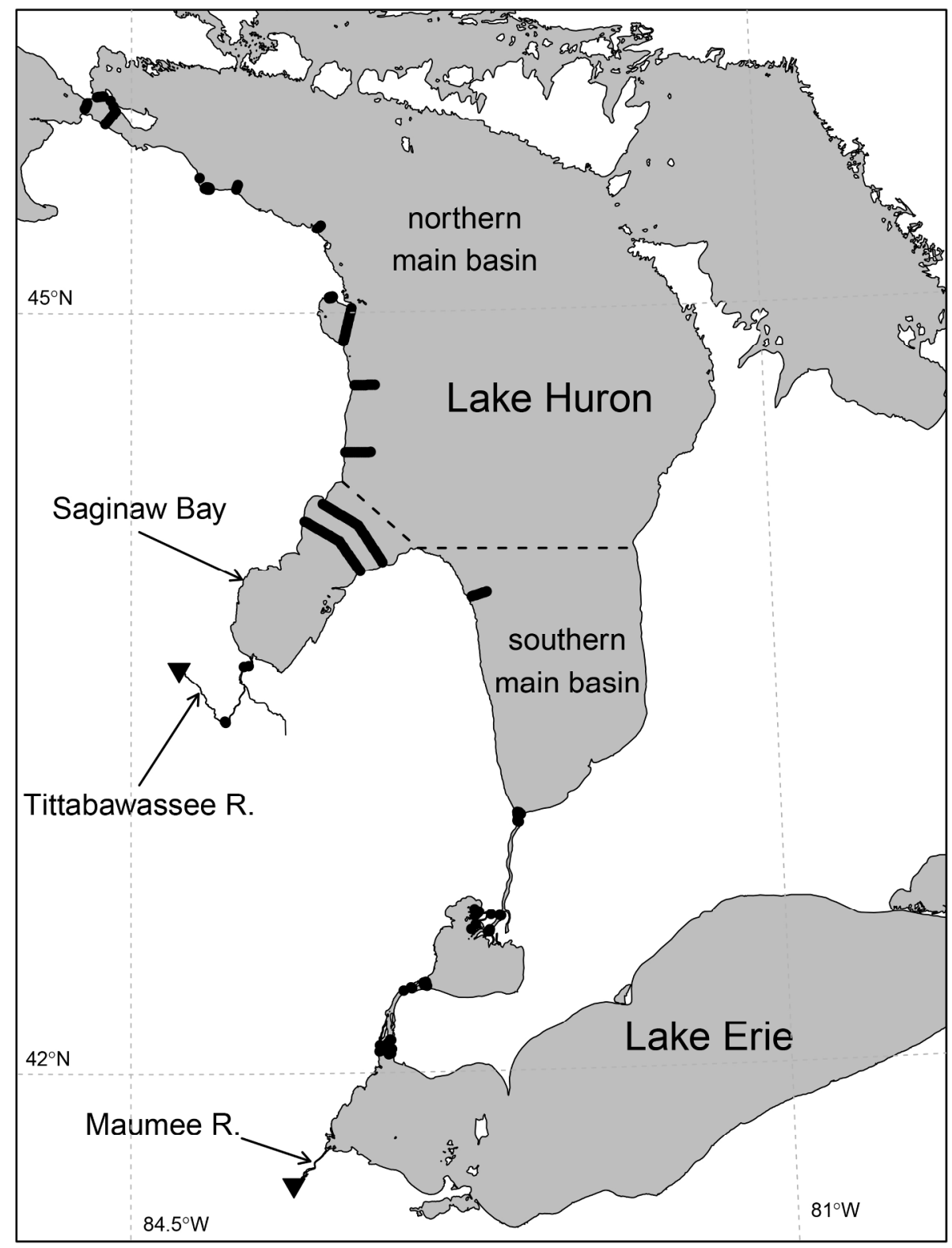

Fig. 1. Map of study area. Solid circles denote locations for acoustic receivers and solid triangles denote tagging locations.

$196 \times 260 \mathrm{~mm}(300 \times 300 \mathrm{DPI})$ 


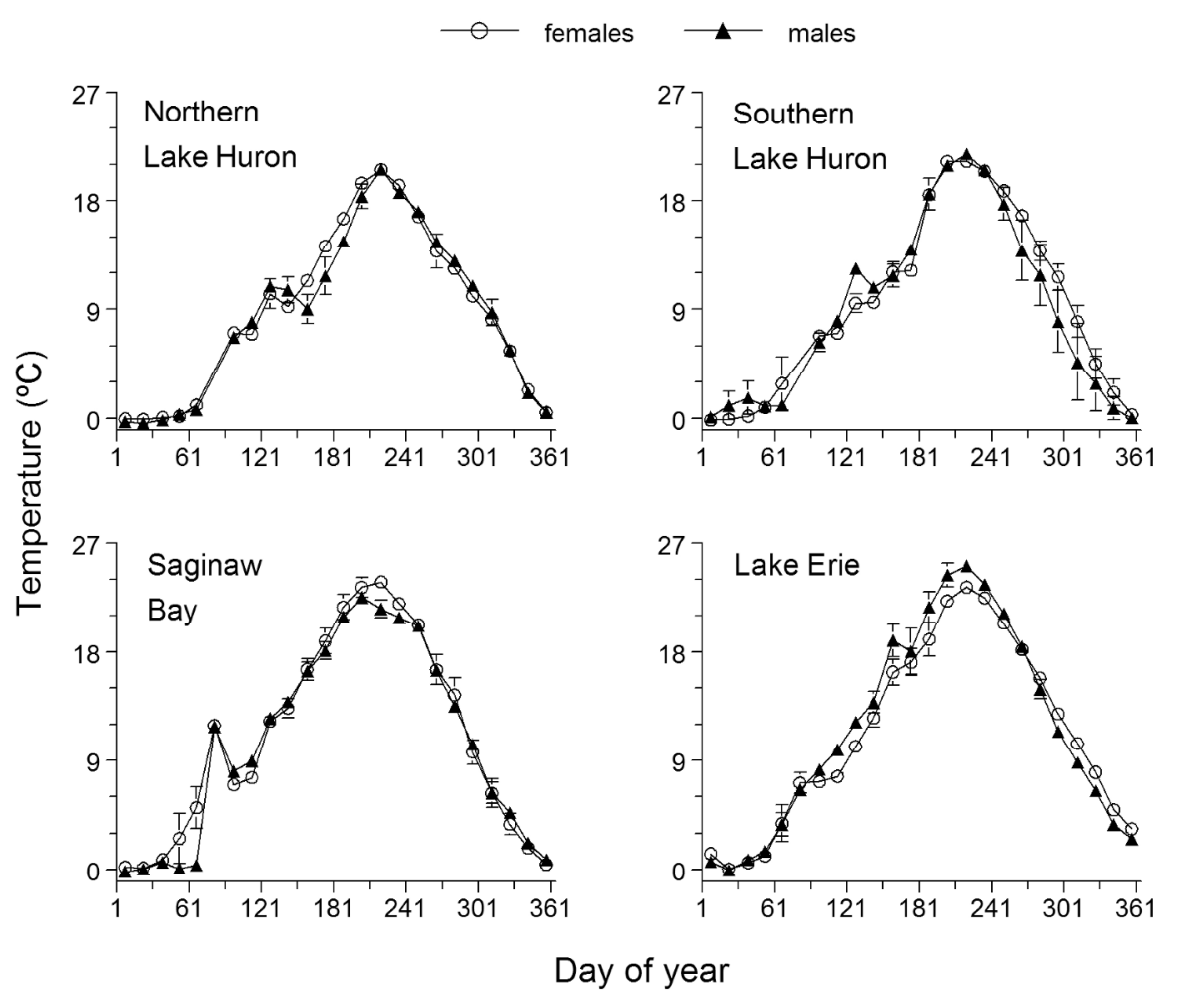

Fig. 2. Temperature regimes experienced by walleye in the northern main basin of Lake Huron, southern main basin of Lake Huron, Saginaw Bay, and Lake Erie, by sex. Each bar represents one standard error. Error bar width may be less than the diameter of the symbol marker used to denote mean temperature, and therefore not visible. See Temperature regimes subsection of Materials and methods section for more details.

$390 \times 300 \mathrm{~mm}(300 \times 300 \mathrm{DPI})$ 

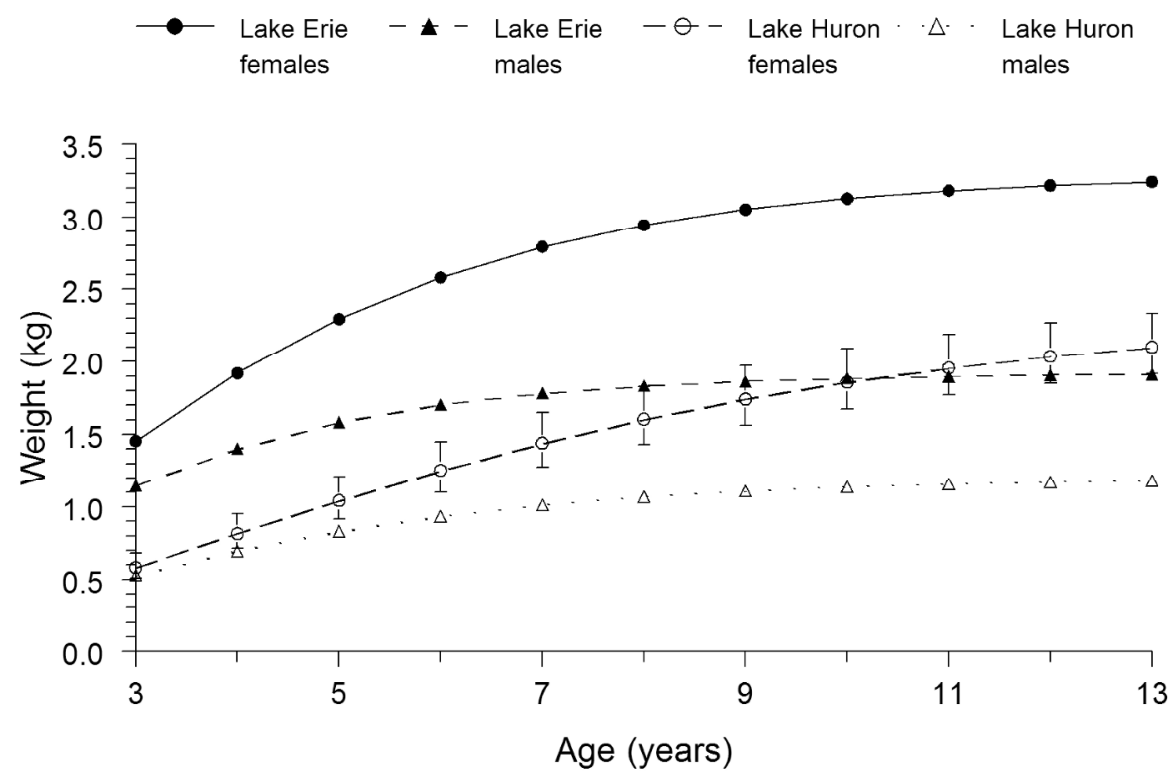

Fig. 3. Growth trajectories for walleye in Lake Huron and Lake Erie, by sex. Estimated weight at age based on gillnet surveys in Saginaw Bay (Lake Huron) during September 2010-2012 and gillnet surveys in Lake Erie during October 2010-2012. Each bar represents one standard error. Error bar width may be less than the diameter of the symbol marker used to denote mean weight at age, and therefore not visible. See Growth trajectories subsection of Materials and methods section for more details.

$390 \times 300 \mathrm{~mm}(300 \times 300 \mathrm{DPI})$ 


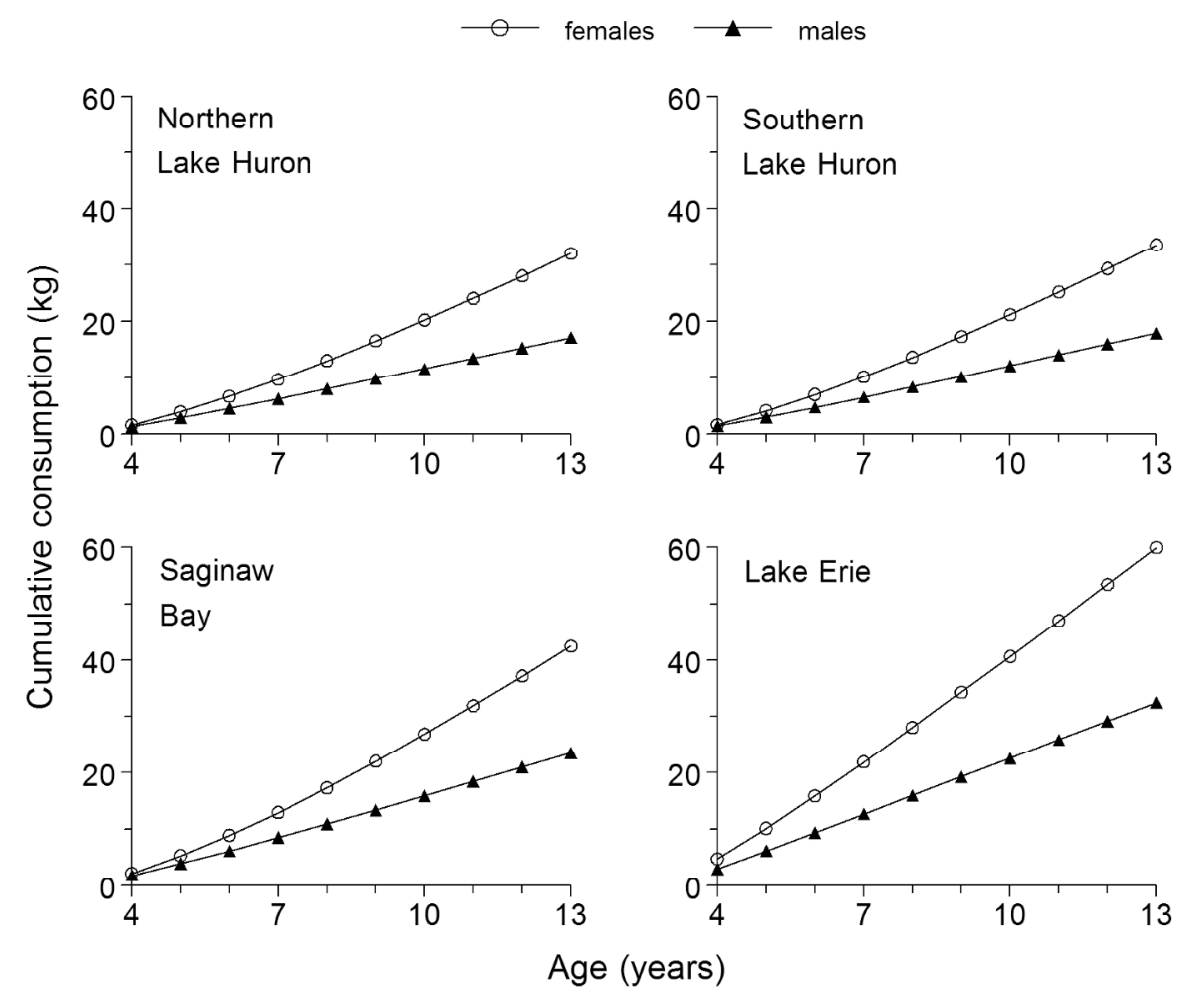

Fig. 4. Cumulative food consumption by walleye, beginning at age 3, in the northern main basin of Lake Huron, southern main basin of Lake Huron, Saginaw Bay, and Lake Erie, by sex. Food consumption estimated by application of a walleye bioenergetics model (Kitchell et al. 1977; Hewett and Johnson 1992) to observed growth trajectories. See Bioenergetics modeling: fit to observed growth subsection of Materials and methods section for more details.

$390 \times 300 \mathrm{~mm}(300 \times 300 \mathrm{DPI})$ 


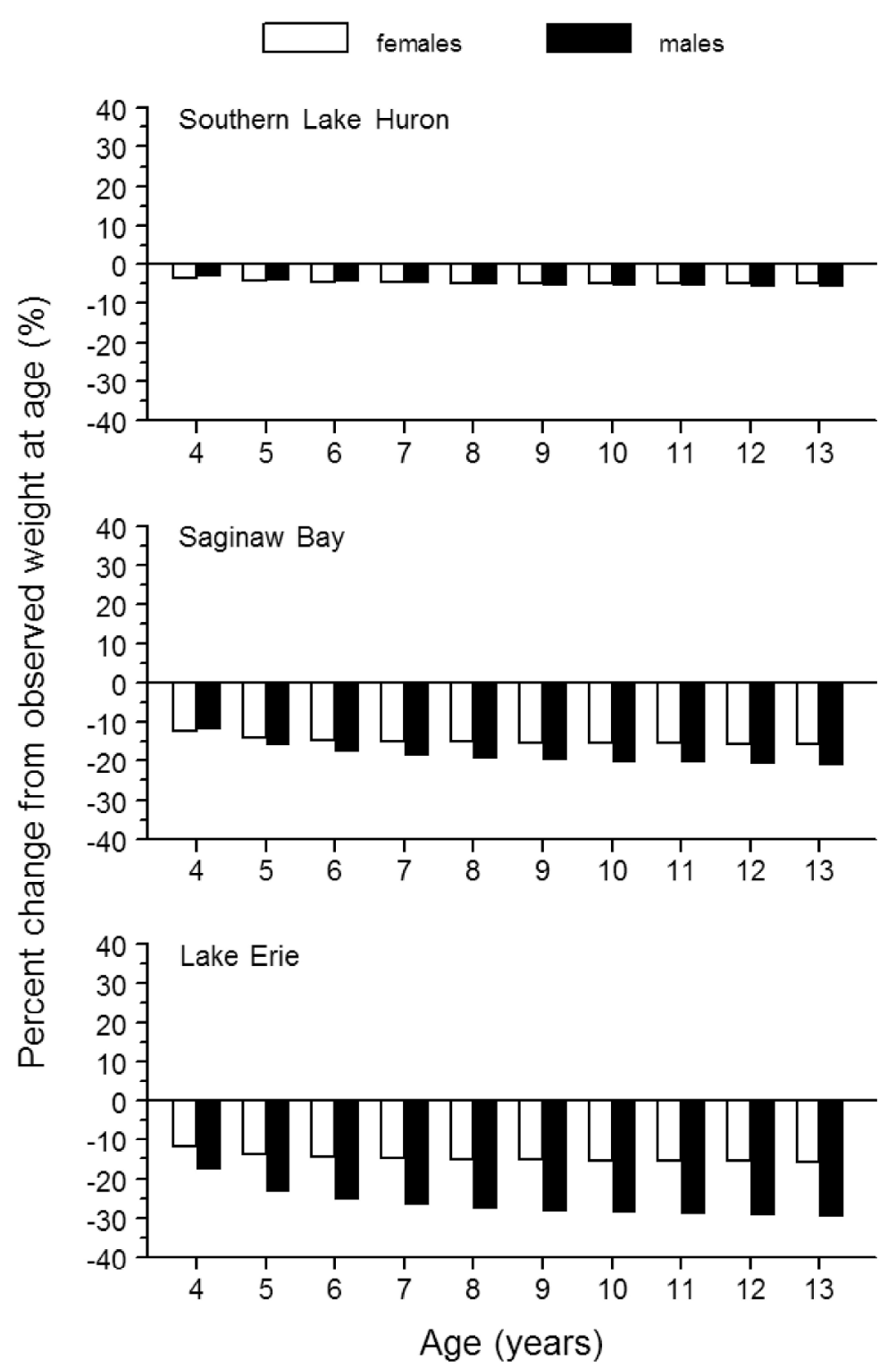

Fig. 5. Predicted changes in walleye weight at age by replacing the temperature regime experienced by walleye in the northern main basin of Lake Huron with the temperature regime for southern main basin of Lake Huron walleye (upper panel), Saginaw Bay walleye (middle panel), and Lake Erie walleye (lower panel), by sex. See Bioenergetics modeling: exchanging temperature regimes between areas and sexes subsection of the Materials and methods section for more details.

$285 \times 369 \mathrm{~mm}(300 \times 300$ DPI $)$ 


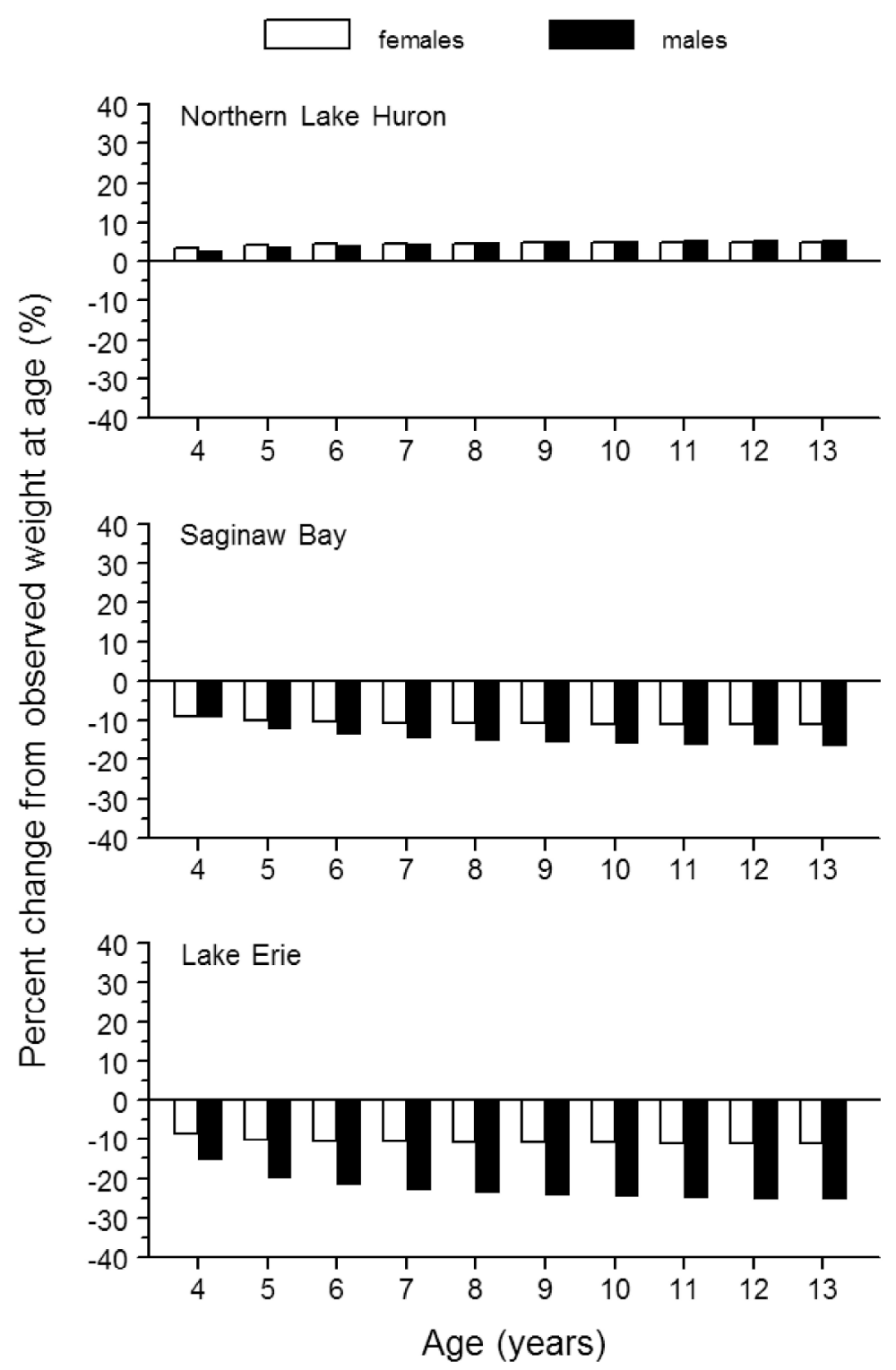

Fig. 6. Predicted changes in walleye weight at age by replacing the temperature regime experienced by walleye in the southern main basin of Lake Huron with the temperature regime for northern main basin of Lake Huron walleye (upper panel), Saginaw Bay walleye (middle panel), and Lake Erie walleye (lower panel), by sex. See Bioenergetics modeling: exchanging temperature regimes between areas and sexes subsection of the Materials and methods section for more details.

$285 \times 369 \mathrm{~mm}(300 \times 300$ DPI $)$ 


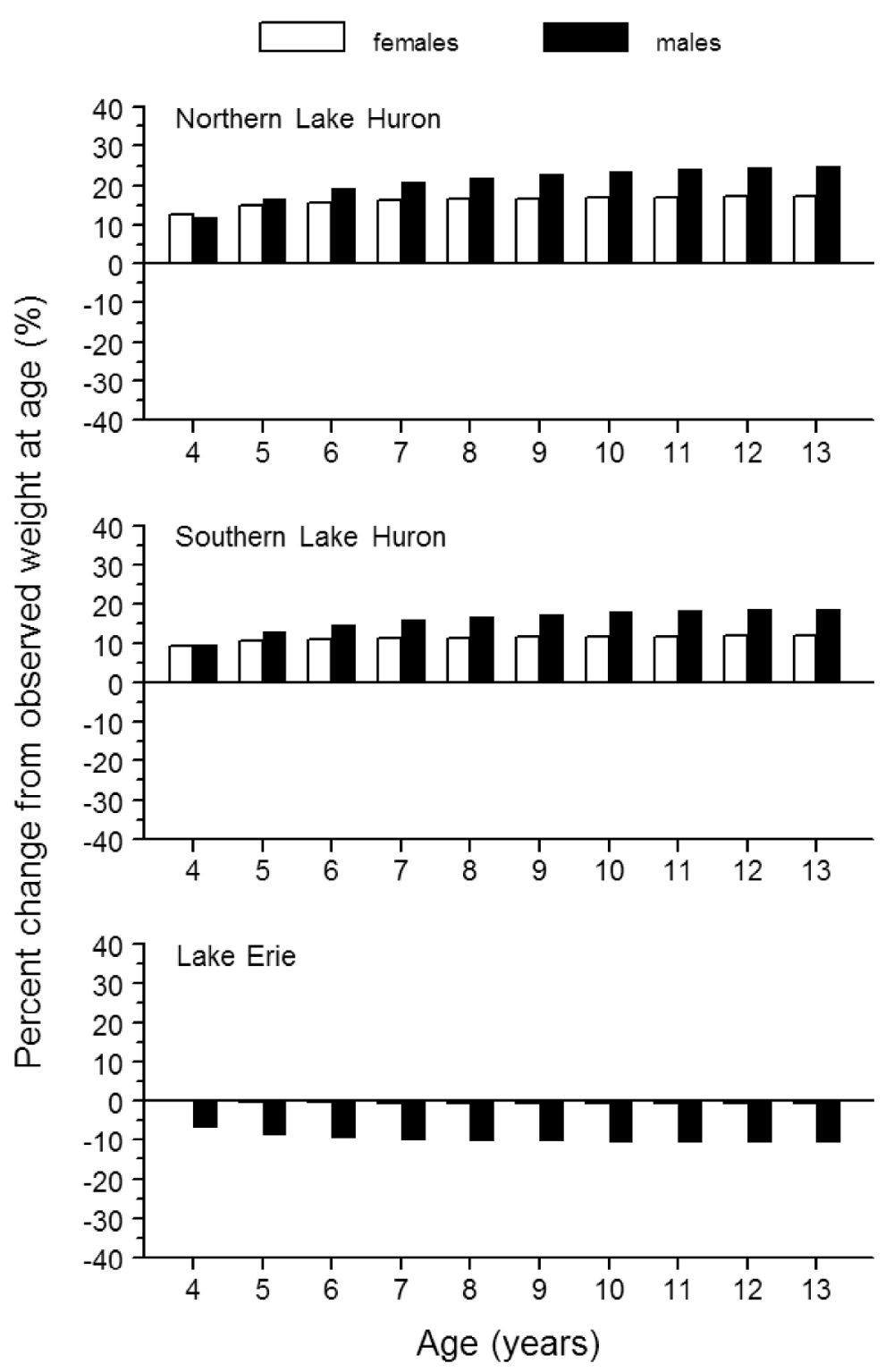

Fig. 7. Predicted changes in walleye weight at age by replacing the temperature regime experienced by walleye in Saginaw Bay with the temperature regime for walleye from the northern main basin of Lake Huron (upper panel), walleye from the southern main basin of Lake Huron (middle panel), and Lake Erie walleye (lower panel), by sex. See Bioenergetics modeling: exchanging temperature regimes between areas and sexes subsection of the Materials and methods section for more details.

$285 \times 369 \mathrm{~mm}(300 \times 300 \mathrm{DPI})$ 


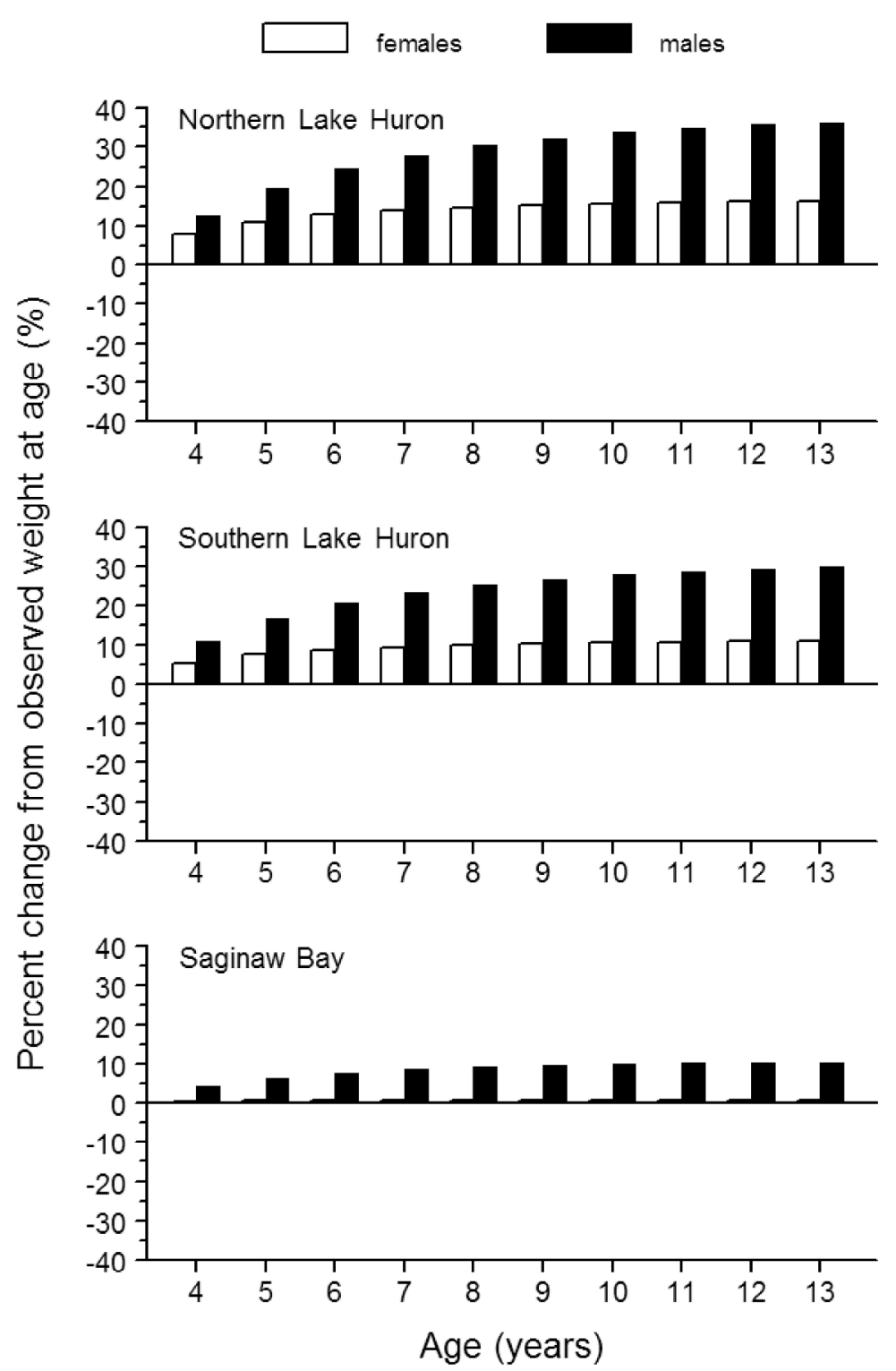

Fig. 8. Predicted changes in walleye weight at age by replacing the temperature regime experienced by walleye in Lake Erie with the temperature regime for walleye from the northern main basin of Lake Huron (upper panel), walleye from the southern main basin of Lake Huron (middle panel), and Saginaw Bay walleye (lower panel), by sex. See Bioenergetics modeling: exchanging temperature regimes between areas and sexes subsection of the Materials and methods section for more details.

$285 \times 369 \mathrm{~mm}(300 \times 300$ DPI $)$ 


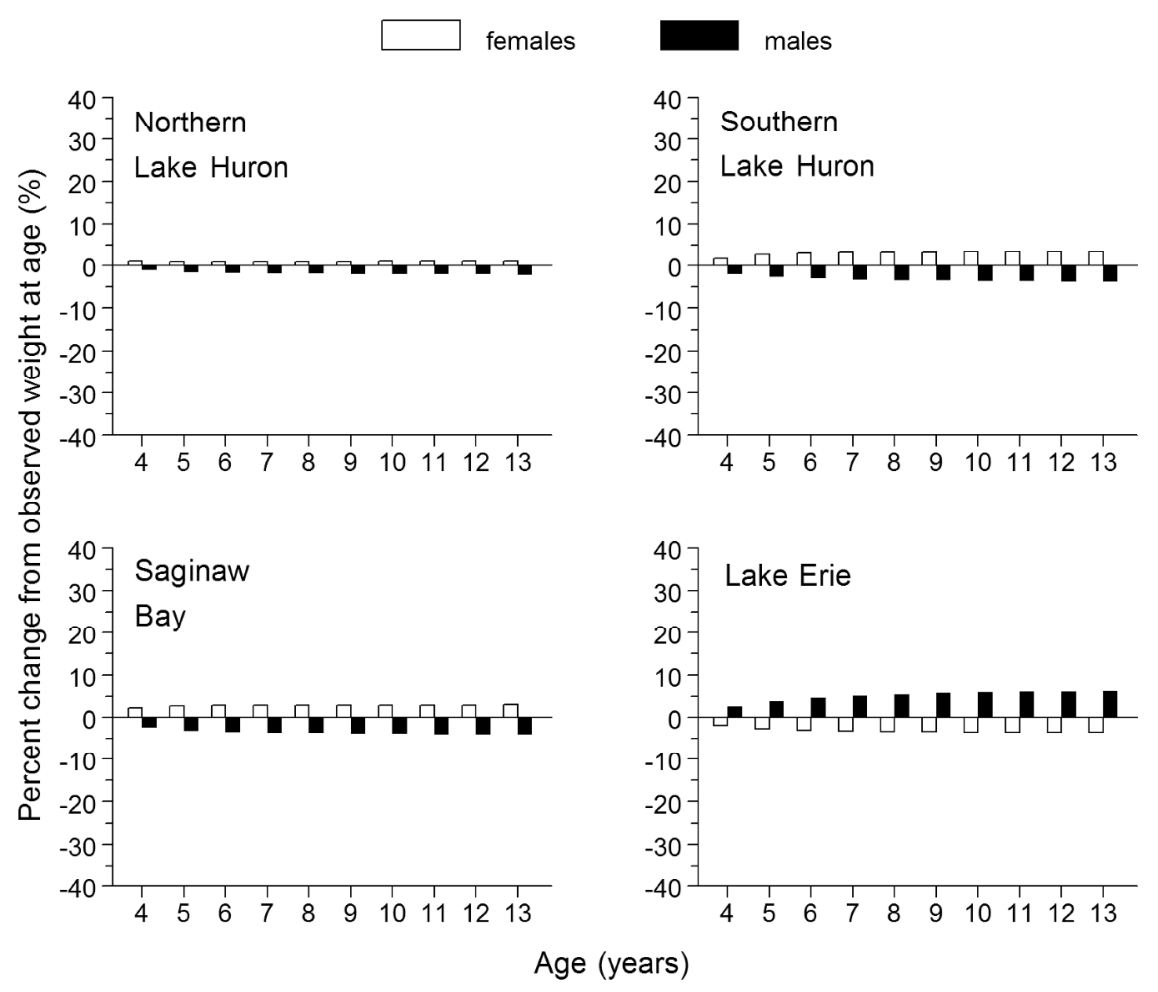

Fig. 9. Predicted changes in walleye weight at age by exchanging temperature regimes experienced by the walleye between the sexes for each of the four geographic areas: northern main basin of Lake Huron, southern main basin of Lake Huron, Saginaw Bay, and Lake Erie. See Bioenergetics modeling: exchanging temperature regimes between areas and sexes subsection of the Materials and methods section for more details.

$390 \times 300 \mathrm{~mm}(300 \times 300 \mathrm{DPI})$ 